\title{
Experimental Characterisation and Numerical Modelling of Residual Stresses in a Nuclear Safe-End Dissimilar Metal Weld Joint
}

\author{
Shuyan Zhang ${ }^{1, *} \mathbb{\oplus}$, Zhuozhi Fan ${ }^{1}$, Jun Li ${ }^{1}$, Shuwen Wen ${ }^{1} \oplus$, Sanjooram Paddea ${ }^{1}$, Lili Lu ${ }^{2}$ and Shiyi Li ${ }^{2}$ \\ 1 Centre of Excellence for Advanced Materials, Dongguan 523808, China; zhuozhi.fan@ceamat.com (Z.F.); \\ jun.li@ceamat.com (J.L.); shuwen.wen@ceamat.com (S.W.); sanjooram.paddea@stress-space.com (S.P.) \\ 2 Science and Technology on Reactor Fuel and Materials Laboratory, Nuclear Power Institute of China, \\ Chengdu 610213, China; lulu1021@163.com (L.L.); lishiyi1124@126.com (S.L.) \\ * Correspondence: shuyan.zhang@ceamat.com; Tel.: +86-0769-23079125
}

\section{check for}

updates

Citation: Zhang, S.; Fan, Z.; Li, J.; Wen, S.; Paddea, S.; Lu, L.; Li, S. Experimental Characterisation and Numerical Modelling of Residual Stresses in a Nuclear Safe-End Dissimilar Metal Weld Joint. Metals 2021, 11, 1298. https://doi.org/ $10.3390 /$ met11081298

Academic Editors:

Foroogh Hosseinzadeh and

Thomas Niendorf

Received: 4 June 2021

Accepted: 11 August 2021

Published: 17 August 2021

Publisher's Note: MDPI stays neutral with regard to jurisdictional claims in published maps and institutional affiliations.

Copyright: (c) 2021 by the authors. Licensee MDPI, Basel, Switzerland. This article is an open access article distributed under the terms and conditions of the Creative Commons Attribution (CC BY) license (https:// creativecommons.org/licenses/by/ $4.0 /)$.
Abstract: In this study, a mock-up of a nuclear safe-end dissimilar metal weld (DMW) joint (SA5083/316L) was manufactured. The manufacturing process involved cladding and buttering of the ferritic steel tube (SA508-3). It was then subjected to a stress relief heat treatment before being girth welded together with the stainless steel tube (316L). The finished mock-up was subsequently machined to its final dimension. The weld residual stresses were thoroughly characterised using neutron diffraction and the contour method. A detailed finite element (FE) modelling exercise was also carried out for the prediction of the weld residual stresses resulting from the manufacturing processes of the DMW joint. Both the experimental and numerical results showed high levels of tensile residual stresses predominantly in the hoop direction of the weld joint in its final machined condition, tending towards the OD surface. The maximum hoop residual stress determined by the contour method was $500 \mathrm{MPa}$, which compared very well with the FE prediction of 467.7 Mpa. Along the neutron scan line at the OD subsurface across the weld joint, both the contour method and the FE modelling gave maximum hoop residual stress near the weld fusion line on the $316 \mathrm{~L}$ side at 388.2 and 453.2 Mpa respectively, whereas the neutron diffraction measured a similar value of $480.6 \mathrm{Mpa}$ in the buttering zone near the SA508-3 side. The results of this research thus demonstrated the reasonable consistency of the three techniques employed in revealing the level and distribution of the residual stresses in the DMW joint for nuclear applications.

Keywords: dissimilar metal weld; welding residual stress; residual stress measurement; contour method; finite element analysis

\section{Introduction}

The structural integrity of the dissimilar metal weld (DMW) joints connecting the ferritic steel pipe nozzles of the pressurized water reactor vessels with the austenitic stainless steel safe-end is critical to the safe operation of nuclear power plants. The safe-end is a pipe segment measuring about $200 \mathrm{~mm}$ long usually made from austenitic stainless steel (typically 316L). One end is connected to the nozzle of the reactor pressure vessel using the specifically designed DMW joint, and the other end is connected to the primary coolant loop pipe (made of stainless steel) using a similar metal weld joint. The pressure vessel, safe-end and primary piping are therefore joined together to form the primary pressure boundary of the nuclear power plant. The DMW is made in the workshop, after the inner wall of the nozzle is cladded and buttering layers added, which is then followed by a stress relief heat treatment procedure. Similar metal welding is then carried out onsite. Both the DMW and the onsite similar metal weld are not post-weld heat treated, in order to avoid the possible sensitization effects. As these welded joints are put into service in the as-welded conditions, it is reasonable to believe that they would contain high levels of tensile residual stress, which is considered to be detrimental. 
It is also known that these DMWs are prone to stress corrosion cracking (SCC) in service operational conditions, and welding residual stresses have been recognised as one of the important factors that promote SCC $[1,2]$. In addition, both the manufacturing induced residual stress and in-service thermal stress could affect the susceptibility to hydrogen embrittlement (HE) of the material, which is closely related to the in-service brittle fracture of a structural component of a nuclear power plant [3]. It is therefore of paramount importance to understand the level and distribution of these residual stresses, as well as their formation and evolution mechanisms, in order to quantify their detrimental effects and ultimately bring them under control in the long run. For this reason, considerable research effort has been devoted into this area so far [4-12].

For example, Coules et al. [4] studied the residual stresses in a Control Rod Drive Mechanism (CRDM) nozzle attachment weld of a Pressurised Water Reactor (PWR) using a deep hole drilling method. They discovered that although modest tensile stresses occurred in the cladding, the attachment weld contained tensile residual stresses of yield magnitude. Guo et al. [5] investigated the laws of stress and strain distribution at the SCC crack tip under the interactive effect of residual stress and mechanical heterogeneity in a nuclear power plant safe-end by means of theoretical analysis and finite element method. Their research results showed that due to the variation of the residual stress, the propagation of the SCC crack might even be paused. Tan et al. [6] investigated the effect of welding residual stress on operating stress in designing a nuclear turbine welded rotor. They employed a 2D axisymmetric finite element model in their study and showed that the operating stress can be affected significantly by the welding residual stress, and the distribution trend of the superposition stress in the weld area was mainly determined by the welding residual stress.

Liu and Wang [7] performed finite element analyses to study the effect of weld overlay sizing on residual stresses of the DMW in PWRs in order to provide a reference for optimizing the weld overlay design. Koo et al. Ref. [8] used cascaded support vector regression (CSVR) to estimate the residual stresses in welded dissimilar metals at nuclear power plants. Song and his partners $[9,10]$ proposed approximate expressions for calculation of through-wall welding residual stress distributions in DMWs of PWR nozzles. In the expressions that they put forward, it was assumed that welding residual stresses were dependent upon the wall thickness of the nozzle, the radius-to-thickness ratio and the 1.0\% proof strengths of the base and weld metals, but not on the safe-end length. Wen et al. [11] conducted a stress analysis for the coolant pump nozzle of a nuclear reactor pressure vessel and found that the ANSYS/WORKBENCH approach was more convenient than the traditional ANSYS APDL method in the geometry modelling, loading and post processing. Liu [12] clarified the effects of a material hardening model and lumped-pass method on a welding residual stress simulation of a J-groove weld in a nuclear RPV (reactor pressure vessel). It was found that based on the kinematic hardening model, the residual stresses simulated with the lumped-pass FE model were almost consistent with those obtained by the pass-by-pass FE model.

Due to the complex nature of the residual stresses in the DMWs, the finite element (FE) modelling technique has been employed in most investigations carried out and reported in the literature. For instance, Dehaghi et al. [13] investigated the residual stresses in feed water nozzle joints in the primary circuit of nuclear power plant reactors using the commercial FE software package ABAQUS. It was discovered that the difference in thermal expansion coefficients between the stainless steel material of the safe-end and the weld metal had led to the creation of tensile residual stresses in the stainless steel zone with high magnitudes. Lee et al. [14] conducted three-dimensional thermal elastic-plastic FE analysis that accurately predicted the residual stress states in the DMWs joining carbon and stainless steel pipes. They found that the axial and hoop residual stresses in the base metal near the weld region on the stainless steel pipe side were higher than those on the carbon steel pipe side in both the inner and outer surfaces. The EPRI/NRC WRS program organized by the Electric Power Research Institute (EPRI) and the U.S. Nuclear Regulatory Commission (NRC) included a round-robin modelling activity on biaxial weld 
residual stress (WRS) mapping for a DMWed nozzle, where a number of research teams submitted their weld modelling results blind to the experimental measurement data [15]. It was found that despite the large spread in the modelling outputs, there was still a level of agreement between the measurement data and model average, both in terms of hoop and axial residual stresses. In this work, the contour method was used to measure the hoop residual stress and the slitting measurement was used to determine the axial residual stress [15]. A few researchers also employed hole-drilling method [1,4,16] and neutron diffraction technique $[17,18]$ to characterise weld residual stresses and validate the modelling results.

On the other hand, attempts were also made to introduce compressive residual stresses in order to suppress crack propagation in the originally deposited weld metal. In trying to do so, Chu et al. [19] used an overlay weld of $10 \mathrm{~mm}$ thick on top of the original stainlesssteel T-pipe joint. The contour method was employed to measure the residual stress in the T-joint and it was shown that compressive residual stress of about $50 \mathrm{Mpa}$ was formed in the original ER316L weld. Ahonen et al. [20] showed in their work that by thermal ageing at $400{ }^{\circ} \mathrm{C}$, the strength mismatch at the SA 508/Alloy 52 of a narrow-gap dissimilar weld could be markedly reduced, which is believed that the effect of strength mismatch reduction at the interface may also help reduce the tensile residual stresses in the weld joint.

From the brief literature review conducted to date, it is highlighted that high level tensile residual stresses of yield magnitude are expected in the nuclear safe-end DMW joints and that the detailed distribution, in particular the through-wall variation, is of significant interest for their safety and structural integrity assessment. Although the various numerical and analytical techniques can provide such data, their validation using equivalent experimental results have been scarce. Like XRD, the hole-drilling technique can only provide surface or near surface measurement. On the other hand, the deep-holedrilling method could be used to measure through-thickness variation of residual stresses, however the measurement results are subject to the selection of measurement location and the accuracy is also sometimes questionable due to low spatial resolution (averaging over the hole diameter). It is well known that both neutron diffraction and the contour method can be used to perform through-thickness residual stress measurements with high spatial resolution as well as accuracy. Nevertheless, up to now there have been few reports on the characterisation of residual stresses of DMWed structures with particular relevance to nuclear applications by using these techniques. It is thus recognised that there is a strong demand for a better understanding of the detailed residual stress distributions in the nuclear safe-end DMW joints through further development of numerical modelling techniques that are validated by experimental data obtained using reliable and thorough experimental characterisation methods, in order to enrich the portfolio of high-fidelity residual stress data.

In this study, a mock-up of a nuclear safe-end DMW joint (SA508-3/316L) is manufactured, and the weld residual stresses are thoroughly characterised using neutron diffraction and the contour method. A detailed finite element modelling exercise is also carried out for the prediction of the weld residual stresses resulting from the manufacturing processes of the DMW joint. Finally, for model validation purposes, the FE modelling results are compared with those of the experiments, and good agreement has been attained.

\section{Manufacture of the Mock-Up}

\subsection{Design and Materials}

Figure 1 shows the mock-up design of the nuclear safe-end DMW joint with dimensions marked before and after machining. Figure 1 a was used in the manufacturing process, giving the details of the cladding and buttering layers as well as the main girth weld joining the ferritic steel and stainless steel tubes ('Weld', Figure 1a). Figure $1 \mathrm{~b}$ gives the final dimension of the weld joint: $\mathrm{OD}=349.2 \mathrm{~mm}, \mathrm{ID}=323.8 \mathrm{~mm}, \mathrm{WT}=12.7 \mathrm{~mm}$, and about $426 \mathrm{~mm}$ in length with the weld centre being measured about $180 \mathrm{~mm}$ from the end of the ferritic steel tube in the actual mock-up. 


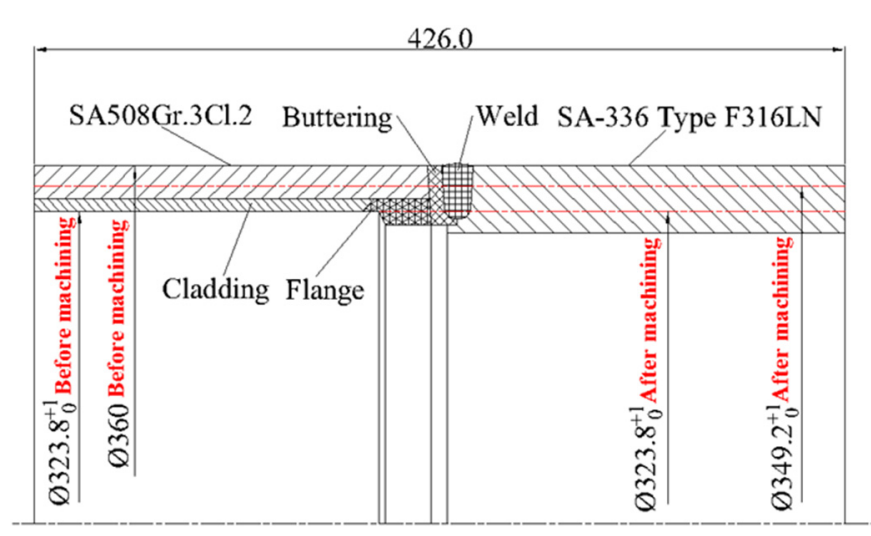

(a)

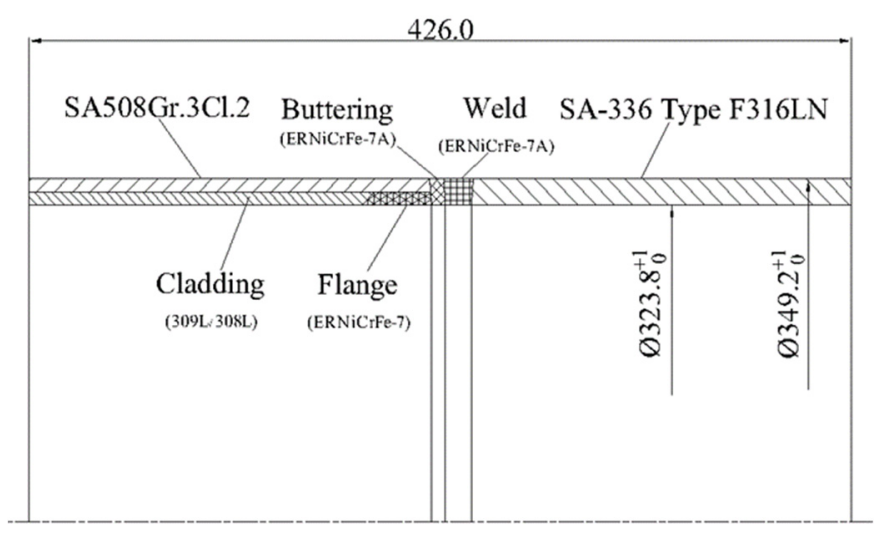

(b)

Figure 1. Mock-up design of the nuclear safe-end DMW joint: (a) manufacture design of the mock-up with radial dimensions marked before (left) and after machining (left); (b) final dimensions of the mock-up after machining (about $426 \mathrm{~mm}$ in length).

Table 1 lists the materials used for the various parts of the mock-up. The ferritic steel tube was acquired in forged, then quenched and tempered condition, and its chemical composition and mechanical properties are given in Tables 2 and 3 respectively. The stainless steel tube was acquired in forged- then solution-treated condition, and its chemical composition and mechanical properties are given in Tables 4 and 5 respectively. Similar details for the welding consumables can be found elsewhere [21,22].

Table 1. Materials used for the various parts of the mock-up.

\begin{tabular}{cccc}
\hline No. & Name & Material & Comments \\
\hline 1 & Ferritic steel tube & SA508-3 & Forged and quenched + tempered \\
2 & Stainless steel tube & 316L & Forged and solution treated \\
3 & Clad layer & ER308L/ER309L & Filler metal \\
4 & Flange & ERNiCrFe-7 & Inconel Welding Electrode 152 \\
5 & Buttering layer & ERNiCrFe-7A & Inconel Filler Metal 52M \\
6 & Girth weld & ERNiCrFe-7A & Inconel Filler Metal 52M \\
\hline
\end{tabular}

Table 2. Chemical composition of the ferritic steel tube.

\begin{tabular}{|c|c|c|c|c|c|c|c|c|c|c|}
\hline Element & $\mathrm{C}$ & Mn & Si & $S$ & $\mathbf{P}$ & $\mathrm{Cr}$ & $\mathrm{Ni}$ & $\mathrm{Cu}$ & Mo & $\mathbf{V}$ \\
\hline Specification & $\leq 0.25$ & $1.20-1.50$ & $0.15-0.40$ & $\leq 0.005$ & $\leq 0.015$ & $0.10-0.25$ & $0.40-1.00$ & $\leq 0.15$ & $0.45-0.60$ & $\leq 0.05$ \\
\hline Actual & 0.17 & 1.48 & 0.25 & 0.003 & 0.007 & 0.18 & 0.96 & 0.05 & 0.47 & 0.001 \\
\hline
\end{tabular}

Table 3. Tensile properties of the ferritic steel tube.

\begin{tabular}{ccccc}
\hline Property & $\begin{array}{c}\text { Yield Strength } \\
\text { (MPa) }\end{array}$ & $\begin{array}{c}\text { Tensile } \\
\text { Strength (MPa) }\end{array}$ & Elongation (\%) & ROA (\%) \\
\hline Specification & $\geq 450$ & $620-795$ & $\geq 16$ & $\geq 35$ \\
Actual & 589 & 711 & 30 & 76 \\
\hline
\end{tabular}

Table 4. Chemical composition of the stainless steel tube.

\begin{tabular}{|c|c|c|c|c|c|c|c|c|c|c|}
\hline Element & $\mathrm{C}$ & Mn & Si & $S$ & $\mathbf{P}$ & $\mathrm{Cr}$ & $\mathrm{Ni}$ & Co & Mo & $\mathbf{N}$ \\
\hline Specification & $\leq 0.030$ & $\leq 2.00$ & $\leq 1.00$ & $\leq 0.005$ & $\leq 0.040$ & $16.0-18.0$ & $10.0-14.0$ & $\leq 0.05$ & $2.00-3.00$ & $0.10-0.16$ \\
\hline Actual & 0.025 & 1.5 & 0.33 & 0.003 & 0.02 & 16.95 & 11.94 & 0.032 & 2.3 & 0.12 \\
\hline
\end{tabular}


Table 5. Tensile properties of the stainless steel tube.

\begin{tabular}{ccccc}
\hline Property & $\begin{array}{c}\text { Yield Strength } \\
\mathbf{( M P a )}\end{array}$ & $\begin{array}{c}\text { Tensile } \\
\text { Strength (MPa) }\end{array}$ & $\begin{array}{c}\text { Elongation } \\
\mathbf{( \% )}\end{array}$ & $\begin{array}{c}\text { ROA } \\
\mathbf{( \% )}\end{array}$ \\
\hline Specification & $\geq 205$ & $\geq 485$ & $\geq 30$ & $\geq 45$ \\
Actual & 299 & 581 & 62 & 77 \\
\hline
\end{tabular}

\subsection{Manufacturing Procedures}

Nuclear grade procedures and specifications were closely followed during the manufacture of the DMW joint mock-up [21,22]. TIG welding was mainly used in the manufacture of the mock-up, either in automatic or manual mode with different filler metal wires (refer to Figure 1 and Table 1) and welding process parameters. The tubes were first clean machined, before cladding the inner surface of the SA508-3 steel tube using an automatic TIG welding process with a pre-heat of $\geq 150^{\circ} \mathrm{C}$. The flange was then manually multi-layer welded, and after the first three layers of welds, a hydrogen removal heat treatment was carried out $\left(250-400^{\circ} \mathrm{C}, \geq 4 \mathrm{~h}\right)$. Afterwards, the buttering layers were automatically welded with a pre-heat of $\geq 150{ }^{\circ} \mathrm{C}$, and after the first three layers, a hydrogen removal heat treatment was again carried out $\left(250-400{ }^{\circ} \mathrm{C}, \geq 4 \mathrm{~h}\right)$. The cladded and buttered SA508-3 steel tube was then subjected to a post-weld stress relief heat treatment at $595-620{ }^{\circ} \mathrm{C}$ for $2-2.5 \mathrm{~h}$. K-type thermocouples were used to monitor and control the temperature, especially for the heating rate control above $350{ }^{\circ} \mathrm{C}$ which was kept at below $55^{\circ} \mathrm{C} / \mathrm{h}$ [22]. It is assumed that after the stress relief heat treatment, the cladded and buttered SA508-3 steel tube would be stress free, hence the cladding and buttering processes were not modelled in the FE analysis and the process parameters not reported.

After the post-weld heat treatment, weld preps were machined on the buttered SA5083 steel tube and the 316L stainless steel tube sides. They were then assembled and fixed together with 6 tack welds of no less than $20 \mathrm{~mm}$ long and $3 \mathrm{~mm}$ wide, equally spaced around the circumference on the inside wall of the tube joint. The whole tube assembly was tack welded onto a rotary positioner which was adjusted so that the axis of the tube assembly was aligned in a horizontal orientation. The final multi-pass girth welding was then carried out automatically using a $\Phi 0.9 \mathrm{~mm}$ ERNiCrFe-7A welding wire. For each weld pass the automatic TIG welding starts from the bottom $\left(180^{\circ}\right.$ position) towards the top $\left(0^{\circ}\right.$ position $)$ on one side and then the other, as shown schematically in Figure 2. A total of 22 weld passes were used to complete the joint and the welding parameters of each pass are listed in Table 6. During the entire welding process the inter-layer temperature of the weldment was controlled at below $177^{\circ} \mathrm{C}$.

Table 6. Welding process parameters used for each pass of the weld joint.

\begin{tabular}{cccccc}
\hline $\begin{array}{c}\text { Pass } \\
\text { No./Layer } \\
\text { No. }\end{array}$ & $\begin{array}{c}\text { Pre-Heat/Inter- } \\
\text { Layer Temp. } \\
\left({ }^{\circ} \mathbf{C}\right)\end{array}$ & $\begin{array}{c}\text { Peak/Base } \\
\text { Current (A) }\end{array}$ & $\begin{array}{c}\text { Peak/Base } \\
\text { Voltage }(\text { V) })\end{array}$ & $\begin{array}{c}\text { Welding } \\
\text { Speed } \\
(\mathbf{m m} / \mathbf{m i n})\end{array}$ & $\begin{array}{c}\text { Wire Feed } \\
\text { Speed } \\
(\mathbf{m m} / \mathbf{m i n})\end{array}$ \\
\hline $1 / 1$ & $14 / 14$ & $220 / 120$ & 9.5 & 85 & 889 \\
$2 / 1$ & $47 / 52$ & $230 / 130$ & 9.6 & 85 & 889 \\
$1 / 2$ & $82 / 89$ & $250 / 150$ & 9.7 & 85 & 889 \\
$2 / 2$ & $96 / 99$ & $250 / 150$ & 9.6 & 85 & 889 \\
$1 / 3$ & $102 / 107$ & $250 / 160$ & 9.8 & 85 & 1143 \\
$2 / 3$ & $117 / 120$ & $260 / 160$ & 9.6 & 85 & 1143 \\
$1 / 4$ & $53 / 56$ & $260 / 160$ & 9.5 & 85 & 1143 \\
$2 / 4$ & $74 / 89$ & $260 / 160$ & 9.6 & 85 & 1143 \\
$1 / 5$ & $132 / 137$ & $260 / 160$ & 9.6 & 85 & 1143 \\
$2 / 5$ & $18 / 18$ & $260 / 160$ & 9.7 & 85 & 1143 \\
$1 / 6$ & $48 / 55$ & $260 / 160$ & 9.6 & 85 & 1143 \\
$2 / 6$ & $78 / 89$ & $260 / 160$ & 9.5 & 85 & 1143 \\
\hline
\end{tabular}


Table 6. Cont.

\begin{tabular}{cccccc}
\hline $\begin{array}{c}\text { Pass } \\
\text { No./Layer } \\
\text { No. }\end{array}$ & $\begin{array}{c}\text { Pre-Heat/Inter- } \\
\text { Layer Temp. } \\
\left({ }^{\circ} \mathbf{C}\right)\end{array}$ & $\begin{array}{c}\text { Peak/Base } \\
\text { Current (A) }\end{array}$ & $\begin{array}{c}\text { Peak/Base } \\
\text { Voltage (V) })\end{array}$ & $\begin{array}{c}\text { Welding } \\
\text { Speed } \\
(\mathbf{m m} / \mathbf{m i n})\end{array}$ & $\begin{array}{c}\text { Wire Feed } \\
\text { Speed } \\
(\mathbf{m m} / \mathbf{m i n})\end{array}$ \\
\hline $1 / 7$ & $68 / 74$ & $260 / 160$ & 9.6 & 85 & 1143 \\
$2 / 7$ & $102 / 107$ & $260 / 160$ & 9.7 & 85 & 1143 \\
$1 / 8$ & $107 / 112$ & $260 / 160$ & 9.6 & 85 & 1143 \\
$2 / 8$ & $110 / 116$ & $260 / 160$ & 9.5 & 85 & 1143 \\
$1 / 9$ & $115 / 124$ & $260 / 160$ & 9.6 & 85 & 1143 \\
$2 / 9$ & $120 / 127$ & $260 / 160$ & 9.6 & 85 & 1143 \\
$1 / 10$ & $124 / 132$ & $260 / 160$ & 9.6 & 85 & 1143 \\
$2 / 10$ & $128 / 138$ & $260 / 160$ & 9.6 & 85 & 1143 \\
$1 / 11$ & $44 / 50$ & $260 / 160$ & 9.8 & 85 & 1143 \\
$2 / 11$ & $48 / 66$ & $260 / 160$ & 9.8 & 85 & 1143 \\
\hline
\end{tabular}

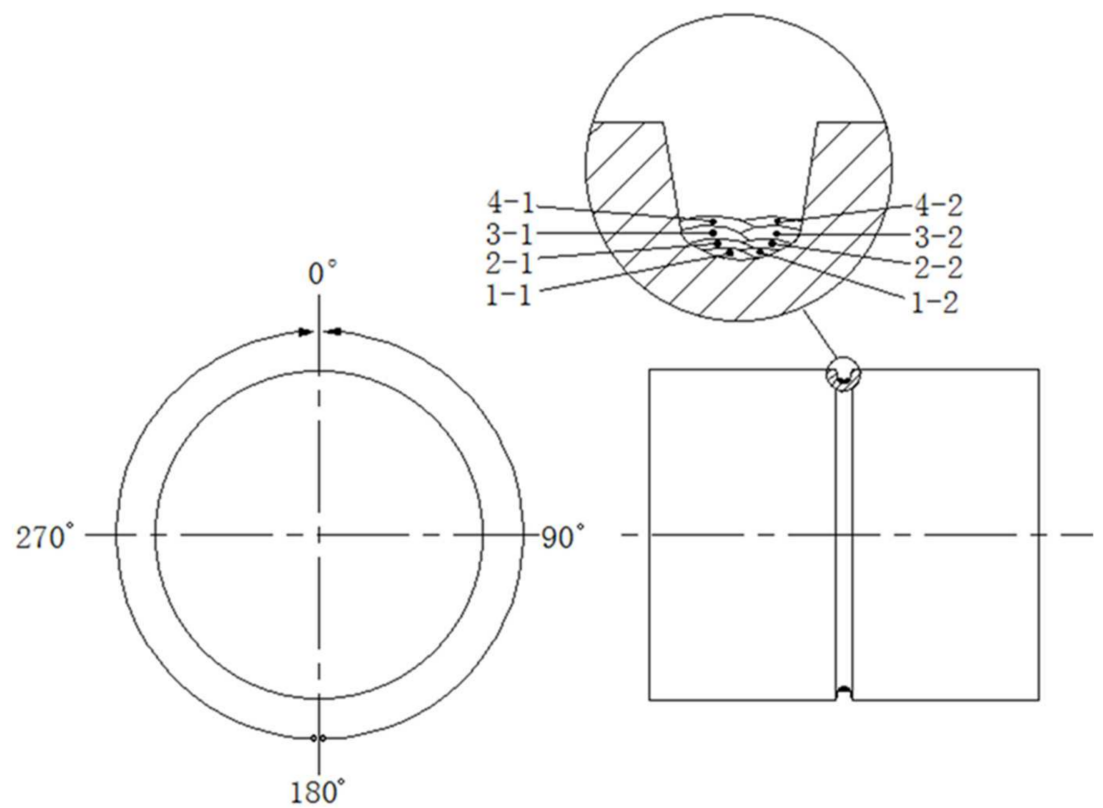

Figure 2. Schematic diagrams of welding directions (left) and welding layers and passes (right).

\section{Experimental Characterisation of Weld Residual Stresses}

\subsection{Neutron Diffraction Method}

The neutron diffraction measurement of residual stresses in the DMW joint of the mock-up was carried out at the ENGIN-X beamline (a spallation neutron source using the time-of-flight technique) at ISIS, Rutherford Appleton Laboratory in Oxford, UK [23]. Prior to the experiment a window was machined in the mock-up tube in order to shorten the neutron path length. Both FE modelling and strain gauge measurement confirmed that the window machining had virtually no influence on the residual stresses near the neutron scanning target area. The extracted window material was first used for macrography of the weld in order to accurately map the measurement points in the neutron measurement space. It was then used to prepare the stress free D0 samples in the form of grooved cylinders ( $4.3 \mathrm{~mm}$ in diameter in order to allow for a $3 \mathrm{~mm} \times 3 \mathrm{~mm} \times 3 \mathrm{~mm}$ gauge volume to be fully immersed), as shown in Figure 3 , for stress free lattice spacing $\left(D_{0}\right)$ measurement. 

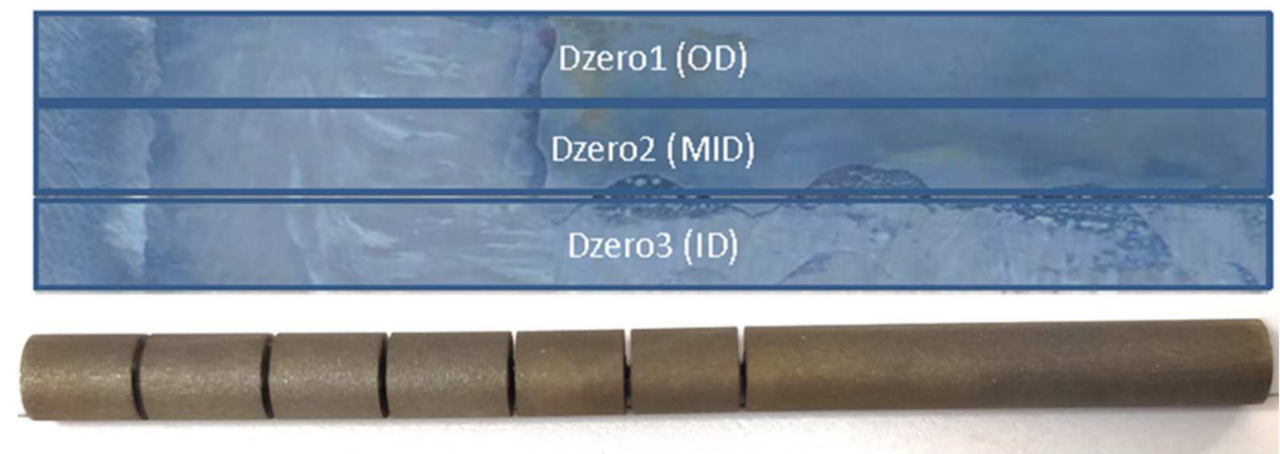

Figure 3. Macrograph of the weld joint (top) and the D0 samples (bottom, grooved cylinder of $4.3 \mathrm{~mm}$ in diameter) machined along the OD, mid thickness (MID) and ID of the weld joint.

The location of the measurement points in the targeted weld area of the mock-up tube is shown in Figure 4, where the stressed lattice spacing $D$ in the axial, hoop and radial directions with respect to the corresponding tube orientations were subsequently measured. The neutron scans were conducted using a nominal gauge volume of $3 \mathrm{~mm} \times 3 \mathrm{~mm} \times 3 \mathrm{~mm}$. To measure the lattice spacing in the hoop direction (along the circumference of the tube), the tube specimen was laid vertical to the floor and the incoming neutron beam was allowed to pass through the pre-cut window. The tube specimen was subsequently laid horizontal to the floor and orientated $45^{\circ}$ to the neutron beam, for measurements of lattice spacing in the axial (along the longitudinal direction of the tube) and radial (through the wall thickness) directions. The normal strains in these directions can therefore be calculated using the following equation:

$$
\varepsilon=\frac{D-D_{0}}{D_{0}}
$$

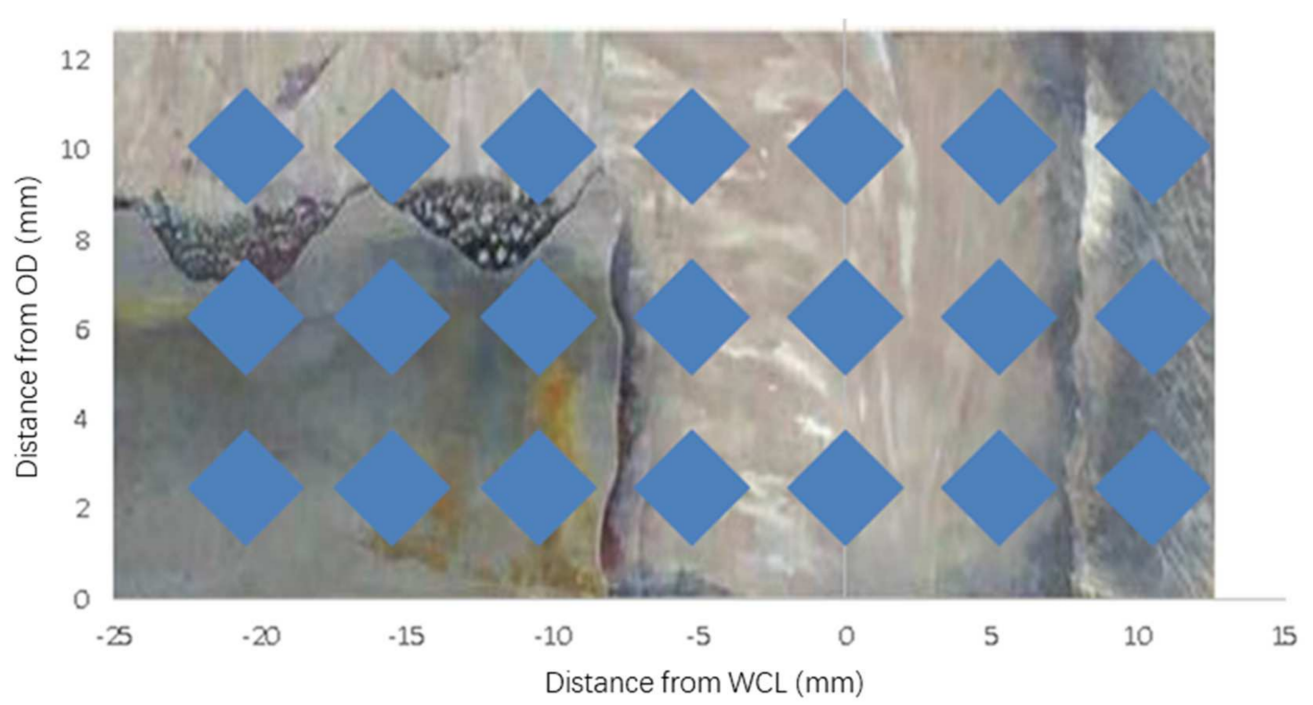

Figure 4. Mapping of the neutron measurement points (blue diamond squares) in the targeted weld area (gauge volume $=3 \mathrm{~mm} \times 3 \mathrm{~mm} \times 3 \mathrm{~mm}$ ).

Assuming that the principal axes of the residual stress field are aligned with the axial, radial and hoop directions, the corresponding residual stress components $\left(\sigma_{11}, \sigma_{22}, \sigma_{33}\right)$ can then be calculated based on the generalised Hooke's Law of linear elasticity:

$$
\begin{aligned}
& \sigma_{11}=\frac{E}{(1+v)(1-2 v)}\left[(1-v) \varepsilon_{11}+v\left(\varepsilon_{22}+\varepsilon_{33}\right)\right] \\
& \sigma_{22}=\frac{E}{(1+v)(1-2 v)}\left[(1-v) \varepsilon_{22}+v\left(\varepsilon_{11}+\varepsilon_{33}\right)\right]
\end{aligned}
$$




$$
\sigma_{33}=\frac{E}{(1+v)(1-2 v)}\left[(1-v) \varepsilon_{33}+v\left(\varepsilon_{22}+\varepsilon_{11}\right)\right]
$$

In the calculation, it was assumed that the materials were elastically isotropic. The values of Young's modulus $(E)$ and Poisson's ratio $(v)$ used for the different materials are listed in Table 7.

Table 7. Elastic constants used for residual stress calculations.

\begin{tabular}{cccc}
\hline Elastic Constants & Fe-Alpha & Fe-Gamma & Nickel \\
\hline$E$, GPa & 211 & 192 & 209 \\
$v$ & 0.29 & 0.3 & 0.31 \\
\hline
\end{tabular}

\subsection{Contour Method}

The contour method for residual stress measurement was first proposed by Prime et al. in $2000[24,25]$. It is basically a destructive method which involves cutting across a plane where the residual stresses need to be determined through the component. Due to the relief of the locked-in residual stresses, the cut plane deforms. This deformation is captured and applied as displacement boundary conditions in a 3D linear elastic FE model to back calculate the 2D distribution of the original residual stress in the component normal to the cut plane [24-26]. As the operations of the contour method are relatively easy and straightforward, it is now widely used for residual stress characterisation. The main advantage here is that it can deal with large components and insensitive to large grained and textured materials.

In the current study, the contour method was used to map the hoop residual stresses of the DMW joint after the neutron diffraction measurement. One cut was performed along the longitudinal plane bisecting the neutron measurement location on one wall. A Sodick wire EDM machine was employed to perform the cut with a $0.25 \mathrm{~mm}$ diameter brass wire and $0.5 \mathrm{~mm} / \mathrm{min}$ cutting speed. The contour of the cut plane was then measured using a Zeiss CMM machine equipped with an optical sensor, with the resolution of the optical sensor set at $0.1 \times 0.1 \mathrm{~mm}^{2}$ spacing.

\section{Numerical Modelling}

\subsection{Geometry and Meshing}

Due to the symmetric nature of the mock-up specimen, a 2D axisymmetric model was built for the FE modelling analysis using ABAQUS CAE (2017, Dassault Systemes, VelizyVillacoublay, France) as shown in Figure 5. The model was partitioned (as illustrated by the different colours) according to the different material zones. The geometric model was then meshed using ABAQUS 2D axisymmetric element type DCAX4 and CAX4R respectively for the thermal and mechanical FE modelling analysis, with adequately refined mesh applied to the dissimilar weld joint as shown in Figure 6.

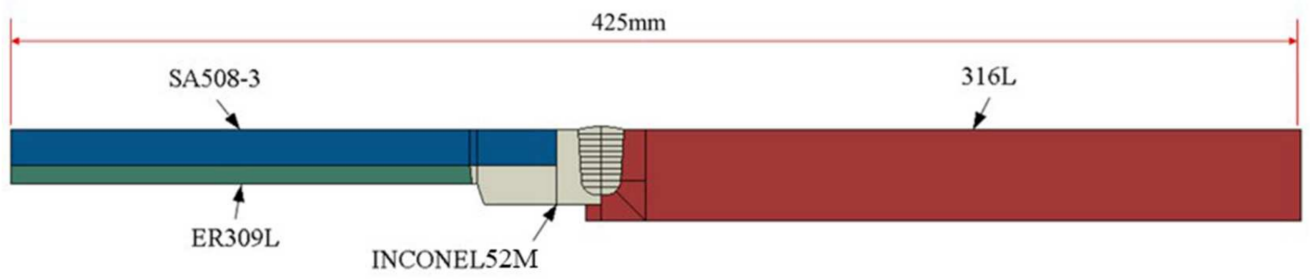

Figure 5. The 2D axisymmetric model of the mock-up with partitions made for different material zones and shown in different colours. 


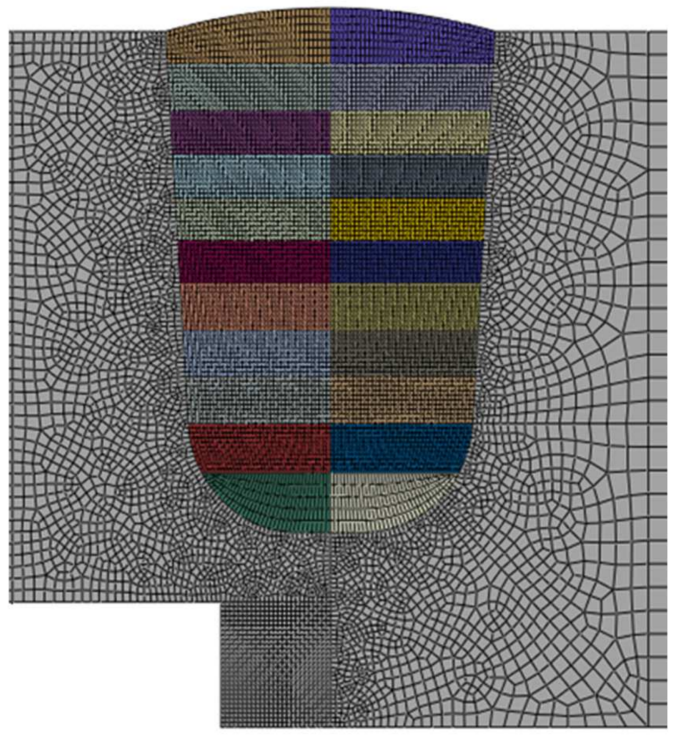

Figure 6. The FE mesh details of the weld joint (different colours represents each idealised weld deposition, which in total counts for 22 welding passes).

\subsection{Material Properties Data}

The thermo-physical and mechanical properties of the different materials involved, namely SA508-3 (ferritic steel tube), 316L (stainless steel tube), ER309L (cladding) and INCONEL52M (buttering and girth weld) alloys, were calculated using the software package JMatPro (V12.1, Sente Software Ltd., Guildford, UK), according to their chemical compositions, some of which are provided in Tables 2 and 4 . The results are listed in Tables 8-15. All the flow stress data were calculated under a quasi-static condition with a strain rate of $0.01 \mathrm{~s}^{-1}$.

Table 8. Thermo-physical properties data of SA508-3.

\begin{tabular}{|c|c|c|c|c|c|c|}
\hline $\begin{array}{c}\text { Temperature } \\
\left({ }^{\circ} \mathrm{C}\right)\end{array}$ & $\begin{array}{l}\text { Density } \\
\left(\mathrm{g} / \mathrm{cm}^{3}\right)\end{array}$ & $\begin{array}{l}\text { Specific Heat } \\
\left(\mathrm{kJ} / \mathrm{kg} /{ }^{\circ} \mathrm{C}\right)\end{array}$ & $\begin{array}{c}\text { Thermal } \\
\text { Conductivity } \\
\left(\mathrm{W} / \mathrm{m} /{ }^{\circ} \mathrm{C}\right)\end{array}$ & $\begin{array}{l}\text { Coefficient of } \\
\text { Thermal Expansion } \\
\times 10^{-6}\left(\mathrm{~mm} / \mathrm{mm} /{ }^{\circ} \mathrm{C}\right)\end{array}$ & $\begin{array}{l}\text { Young's } \\
\text { Modulus } \\
\text { (GPa) }\end{array}$ & $\begin{array}{c}\text { Poisson's } \\
\text { Ratio }\end{array}$ \\
\hline 25 & 7.85 & 0.450 & 41.0 & 12.5 & 210.9 & 0.289 \\
\hline 100 & 7.83 & 0.481 & 41.8 & 12.7 & 207.1 & 0.292 \\
\hline 200 & 7.80 & 0.520 & 41.7 & 13.1 & 201.8 & 0.296 \\
\hline 300 & 7.77 & 0.564 & 40.5 & 13.5 & 193.9 & 0.300 \\
\hline 400 & 7.73 & 0.618 & 38.6 & 13.8 & 184.1 & 0.304 \\
\hline 500 & 7.70 & 0.688 & 36.3 & 14.2 & 172.3 & 0.308 \\
\hline 600 & 7.66 & 0.786 & 34.0 & 14.6 & 159.1 & 0.311 \\
\hline 700 & 7.64 & 1.131 & 29.8 & 13.8 & 142.2 & 0.322 \\
\hline 800 & 7.66 & 0.594 & 26.0 & 11.0 & 127.5 & 0.339 \\
\hline 900 & 7.60 & 0.609 & 27.3 & 12.5 & 117.7 & 0.345 \\
\hline 1000 & 7.55 & 0.624 & 28.5 & 13.8 & 107.7 & 0.351 \\
\hline 1100 & 7.50 & 0.640 & 29.7 & 14.9 & 97.6 & 0.357 \\
\hline 1200 & 7.44 & 0.655 & 31.0 & 15.6 & 87.4 & 0.363 \\
\hline 1300 & 7.39 & 0.671 & 32.2 & 16.4 & 77.0 & 0.369 \\
\hline 1400 & 7.34 & 0.687 & 33.4 & 17.0 & 66.5 & 0.375 \\
\hline
\end{tabular}


Table 9. Flow stress of SA508-3 at different temperatures.

\begin{tabular}{|c|c|c|c|c|c|c|c|c|}
\hline $\begin{array}{c}\text { Plastic Strain } \\
(\%)\end{array}$ & 0 & 4 & 8 & 12 & 16 & 20 & 24 & 28 \\
\hline $\begin{array}{c}\text { Temperature } \\
\left({ }^{\circ} \mathrm{C}\right)\end{array}$ & \multicolumn{8}{|c|}{ True Stress (MPa) } \\
\hline 25 & 420 & 625 & 685 & 723 & 751 & 773 & 792 & 809 \\
\hline 200 & 301 & 459 & 506 & 535 & 557 & 575 & 590 & 603 \\
\hline 500 & 244 & 376 & 415 & 440 & 459 & 474 & 487 & 498 \\
\hline 700 & 220 & 335 & 369 & 390 & 406 & 411 & 405 & 399 \\
\hline 900 & 56 & 70 & 70 & 70 & 69 & 69 & 68 & 68 \\
\hline 1100 & 26 & 26 & 26 & 26 & 26 & 26 & 26 & 25 \\
\hline 1400 & 6.0 & 6.0 & 6.0 & 6.0 & 6.0 & 6.0 & 6.0 & 6.0 \\
\hline
\end{tabular}

Table 10. Thermo-physical properties data of 316L.

\begin{tabular}{|c|c|c|c|c|c|c|}
\hline $\begin{array}{c}\text { Temperature } \\
\left({ }^{\circ} \mathrm{C}\right)\end{array}$ & $\begin{array}{l}\text { Density } \\
\left(\mathrm{g} / \mathrm{cm}^{3}\right)\end{array}$ & $\begin{array}{l}\text { Specific Heat } \\
\left(\mathrm{kJ} / \mathrm{kg} /{ }^{\circ} \mathrm{C}\right)\end{array}$ & $\begin{array}{c}\text { Thermal } \\
\text { Conductivity } \\
\left(\mathrm{W} / \mathrm{m} /{ }^{\circ} \mathrm{C}\right)\end{array}$ & $\begin{array}{c}\text { Coefficient of } \\
\text { Thermal Expansion } \\
\times 10^{-6}\left(\mathrm{~mm} / \mathrm{mm} /{ }^{\circ} \mathrm{C}\right)\end{array}$ & $\begin{array}{l}\text { Young's } \\
\text { Modulus } \\
\text { (GPa) }\end{array}$ & $\begin{array}{c}\text { Poisson's } \\
\text { Ratio }\end{array}$ \\
\hline 25 & 7.99 & 0.447 & 13.67 & 18.85 & 194.3 & 0.298 \\
\hline 100 & 7.96 & 0.468 & 14.67 & 18.99 & 189.2 & 0.301 \\
\hline 200 & 7.92 & 0.489 & 16.00 & 19.20 & 182.2 & 0.306 \\
\hline 300 & 7.87 & 0.507 & 17.34 & 19.42 & 175.0 & 0.310 \\
\hline 400 & 7.82 & 0.524 & 18.68 & 19.65 & 167.8 & 0.315 \\
\hline 500 & 7.77 & 0.540 & 20.01 & 19.89 & 160.4 & 0.319 \\
\hline 600 & 7.73 & 0.557 & 21.35 & 20.13 & 152.8 & 0.324 \\
\hline 700 & 7.68 & 0.574 & 22.69 & 20.38 & 145.2 & 0.328 \\
\hline 800 & 7.63 & 0.592 & 24.02 & 20.65 & 137.4 & 0.333 \\
\hline 900 & 7.58 & 0.610 & 25.36 & 20.92 & 129.4 & 0.337 \\
\hline 1000 & 7.53 & 0.628 & 26.69 & 21.20 & 121.3 & 0.342 \\
\hline 1100 & 7.48 & 0.648 & 28.03 & 21.50 & 113.1 & 0.346 \\
\hline 1200 & 7.43 & 0.668 & 29.36 & 21.79 & 104.8 & 0.351 \\
\hline 1300 & 7.37 & 0.688 & 30.70 & 22.09 & 96.3 & 0.355 \\
\hline 1400 & 7.32 & 0.856 & 32.28 & 22.34 & 86.3 & 0.359 \\
\hline
\end{tabular}

Table 11. Flow stress of 316L at different temperatures.

\begin{tabular}{ccccccccc}
\hline $\begin{array}{c}\text { Plastic Strain } \\
(\%)\end{array}$ & $\mathbf{0}$ & $\mathbf{4}$ & $\mathbf{8 . 3}$ & $\mathbf{1 2 . 7}$ & $\mathbf{1 7 . 3}$ & $\mathbf{2 2 . 1}$ & $\mathbf{2 4 . 6}$ & $\mathbf{2 7 . 1}$ \\
\hline $\begin{array}{c}\text { Temperature } \\
\left({ }^{\circ} \mathbf{C}\right)\end{array}$ & & \multicolumn{7}{c}{ True Stress (MPa) } \\
\hline 25 & 362 & 613 & 671 & 697 & 707 & 708 & 707 & 704 \\
200 & 265 & 507 & 571 & 602 & 618 & 625 & 626 & 626 \\
500 & 219 & 426 & 481 & 508 & 523 & 529 & 531 & 531 \\
700 & 207 & 373 & 414 & 433 & 441 & 444 & 444 & 443 \\
900 & 153 & 147 & 141 & 135 & 129 & 123 & 119 & 116 \\
1100 & 39 & 38 & 36 & 35 & 33 & 31 & 31 & 30 \\
1400 & 6 & 6 & 6 & 6 & 6 & 6 & 6 & 6 \\
\hline
\end{tabular}


Table 12. Thermo-physical properties data of ER309L.

\begin{tabular}{|c|c|c|c|c|c|c|}
\hline $\begin{array}{c}\text { Temperature } \\
\left({ }^{\circ} \mathrm{C}\right)\end{array}$ & $\begin{array}{l}\text { Density } \\
\left(\mathrm{g} / \mathrm{cm}^{3}\right)\end{array}$ & $\begin{array}{l}\text { Specific Heat } \\
\left(\mathrm{kJ} / \mathrm{kg} /{ }^{\circ} \mathrm{C}\right)\end{array}$ & $\begin{array}{c}\text { Thermal } \\
\text { Conductivity } \\
\left(\mathrm{W} / \mathrm{m} /{ }^{\circ} \mathrm{C}\right)\end{array}$ & $\begin{array}{c}\text { Coefficient of } \\
\text { Thermal Expansion } \\
\times 10^{-6}\left(\mathrm{~mm} / \mathrm{mm} /{ }^{\circ} \mathrm{C}\right)\end{array}$ & $\begin{array}{l}\text { Young's } \\
\text { Modulus } \\
\text { (GPa) }\end{array}$ & $\begin{array}{c}\text { Poisson's } \\
\text { Ratio }\end{array}$ \\
\hline 25 & 7.94 & 0.449 & 13.80 & 18.4 & 193.8 & 0.299 \\
\hline 100 & 7.90 & 0.470 & 14.79 & 18.6 & 188.8 & 0.302 \\
\hline 200 & 7.86 & 0.492 & 16.11 & 18.8 & 181.9 & 0.306 \\
\hline 300 & 7.81 & 0.510 & 17.43 & 19.1 & 174.9 & 0.311 \\
\hline 400 & 7.77 & 0.527 & 18.75 & 19.3 & 167.7 & 0.315 \\
\hline 500 & 7.72 & 0.544 & 20.07 & 19.6 & 160.3 & 0.319 \\
\hline 600 & 7.67 & 0.561 & 21.39 & 19.8 & 152.8 & 0.324 \\
\hline 700 & 7.63 & 0.629 & 22.70 & 20.1 & 145.1 & 0.328 \\
\hline 800 & 7.58 & 0.608 & 24.34 & 20.5 & 136.0 & 0.333 \\
\hline 900 & 7.52 & 0.616 & 25.68 & 20.9 & 128.0 & 0.337 \\
\hline 1000 & 7.47 & 0.635 & 27.02 & 21.2 & 120.0 & 0.341 \\
\hline 1100 & 7.42 & 0.655 & 28.36 & 21.5 & 112.0 & 0.346 \\
\hline 1200 & 7.37 & 0.676 & 29.70 & 21.8 & 103.9 & 0.350 \\
\hline 1300 & 7.32 & 0.698 & 31.03 & 22.1 & 95.5 & 0.354 \\
\hline 1400 & 7.27 & 0.849 & 32.79 & 22.3 & 84.2 & 0.358 \\
\hline
\end{tabular}

Table 13. Flow stress of ER309L at different temperatures.

\begin{tabular}{ccccccccc}
\hline $\begin{array}{c}\text { Plastic Strain } \\
(\mathbf{\%})\end{array}$ & $\mathbf{0}$ & $\mathbf{4}$ & $\mathbf{8}$ & $\mathbf{1 2}$ & $\mathbf{1 6}$ & $\mathbf{2 0}$ & $\mathbf{2 4}$ & $\mathbf{2 8}$ \\
\hline $\begin{array}{c}\text { Temperature } \\
\left({ }^{\circ} \mathbf{C}\right)\end{array}$ & & & \multicolumn{7}{c}{ True Stress (MPa) } \\
\hline 25 & 383 & 574 & 631 & 666 & 692 & 714 & 731 & 747 \\
200 & 273 & 418 & 462 & 489 & 510 & 526 & 540 & 552 \\
500 & 221 & 343 & 380 & 403 & 420 & 434 & 445 & 455 \\
700 & 132 & 132 & 131 & 130 & 128 & 126 & 125 & 124 \\
900 & 24 & 24 & 24 & 23 & 23 & 23 & 22 & 22 \\
1100 & 6.5 & 6.5 & 6.5 & 6.4 & 6.3 & 6.2 & 6.1 & 6.1 \\
1400 & 1.5 & 1.4 & 1.4 & 1.4 & 1.4 & 1.4 & 1.4 & 1.4 \\
\hline
\end{tabular}

Table 14. Thermo-physical properties data of INCONEL52M.

\begin{tabular}{|c|c|c|c|c|c|c|}
\hline $\begin{array}{c}\text { Temperature } \\
\left({ }^{\circ} \mathrm{C}\right)\end{array}$ & $\begin{array}{l}\text { Density } \\
\left(\mathrm{g} / \mathrm{cm}^{3}\right)\end{array}$ & $\begin{array}{l}\text { Specific Heat } \\
\left(\mathrm{kJ} / \mathrm{kg} /{ }^{\circ} \mathrm{C}\right)\end{array}$ & $\begin{array}{c}\text { Thermal } \\
\text { Conductivity } \\
\left(\mathrm{W} / \mathrm{m} /{ }^{\circ} \mathrm{C}\right)\end{array}$ & $\begin{array}{c}\text { Coefficient of } \\
\text { Thermal Expansion } \\
\times 10^{-6}\left(\mathrm{~mm} / \mathrm{mm} /{ }^{\circ} \mathrm{C}\right)\end{array}$ & $\begin{array}{l}\text { Young's } \\
\text { Modulus } \\
\text { (GPa) }\end{array}$ & $\begin{array}{c}\text { Poisson's } \\
\text { Ratio }\end{array}$ \\
\hline 25 & 8.19 & 0.435 & 13.03 & 12.35 & 214.3 & 0.311 \\
\hline 100 & 8.17 & 0.452 & 14.34 & 12.68 & 209.5 & 0.313 \\
\hline 200 & 8.14 & 0.470 & 16.07 & 13.14 & 202.8 & 0.317 \\
\hline 300 & 8.10 & 0.488 & 17.79 & 13.60 & 195.8 & 0.320 \\
\hline 400 & 8.07 & 0.505 & 19.49 & 14.06 & 188.6 & 0.323 \\
\hline 500 & 8.03 & 0.522 & 21.17 & 14.51 & 181.2 & 0.327 \\
\hline 600 & 7.99 & 0.666 & 22.84 & 14.96 & 173.5 & 0.330 \\
\hline 700 & 7.94 & 0.708 & 23.23 & 15.83 & 162.7 & 0.332 \\
\hline 800 & 7.89 & 0.581 & 23.98 & 16.68 & 152.0 & 0.333 \\
\hline 900 & 7.84 & 0.604 & 25.54 & 17.15 & 143.6 & 0.336 \\
\hline 1000 & 7.79 & 0.629 & 27.09 & 17.64 & 134.8 & 0.339 \\
\hline 1100 & 7.74 & 0.644 & 28.64 & 18.13 & 125.8 & 0.342 \\
\hline 1200 & 7.69 & 0.668 & 30.20 & 18.62 & 116.7 & 0.345 \\
\hline 1300 & 7.64 & 0.693 & 31.76 & 19.11 & 107.4 & 0.348 \\
\hline
\end{tabular}


Table 15. Flow stress of INCONEL52M at different temperatures.

\begin{tabular}{ccccccccc}
\hline $\begin{array}{c}\text { Plastic Strain } \\
(\mathbf{\%})\end{array}$ & $\mathbf{0}$ & $\mathbf{4}$ & $\mathbf{8}$ & $\mathbf{1 2}$ & $\mathbf{1 6}$ & $\mathbf{2 0}$ & $\mathbf{2 4}$ & $\mathbf{2 8}$ \\
\hline $\begin{array}{c}\text { Temperature } \\
\left({ }^{\circ} \mathbf{C}\right)\end{array}$ & & \multicolumn{7}{c}{ True Stress (MPa) } \\
\hline 25 & 361 & 637 & 726 & 784 & 828 & 864 & 894 & 920 \\
200 & 277 & 545 & 637 & 698 & 745 & 784 & 816 & 845 \\
500 & 240 & 476 & 556 & 609 & 650 & 684 & 713 & 739 \\
700 & 229 & 407 & 407 & 406 & 405 & 402 & 399 & 396 \\
900 & 92 & 92 & 92 & 92 & 92 & 92 & 91 & 90 \\
1100 & 25 & 25 & 25 & 25 & 25 & 25 & 24 & 24 \\
1300 & 8 & 8 & 8 & 8 & 8 & 8 & 8 & 8 \\
\hline
\end{tabular}

\subsection{Computational Procedures}

After the 2D FE model creation and meshing (see Figures 5 and 6), different material properties were assigned to the appropriate partition regions. As stress relief heat treatment was carried out after the cladding and buttering of the SA508-3 steel tube, it was assumed that both tubes were in a stress free condition before the final DMW joint was made. Therefore, only the multi-pass girth welding process and the final machining of the tube assembly were considered in the following FE modelling analysis of this study, and in both cases ABAQUS Standard (an implicit FE solver, 2017, Dassault Systemes, Velizy-Villacoublay, France) was used with a combined isotropic-kinematic hardening model applied where appropriate. A sequentially coupled thermo-mechanical modelling approach was adopted. A thermal analysis was performed first to calculate the thermal history of the weldment during the girth welding process. It was then followed by a mechanical analysis in which the temperature history predicted in the thermal analysis was used as a thermal loading condition in order to calculate the transient stress and strain response of the weldment during the girth welding process, and thus the prediction of its final residual stress field. In the mechanical analysis step, the ABAQUS implicit elastoplastic FE formulation was adopted, which is capable of modelling large deformation with the consideration of contact and nonlinear geometry. Metallurgical transformations of SA508-3 steel were neglected in the present study. This is considered to have minimal effect on the FE modelling results, as the girth weld is connected with the buttering layer on the ferritic steel tube side with the heat affected zone (HAZ) confined within it.

After modelling of the girth welding process, the FE model was rebuilt for modelling of the final machining process, with the geometrical profile of the specimen inherited from the previous modelling step. The same element type as that used in the mechanical analysis of the girth welding process was assigned to the whole domain which was partitioned to contain the final geometry and the areas to be removed by the machining process, as shown in Figure 7. The MAP SOLUTION function in ABAQUS was used to map the stress and strain results from the mechanical analysis of the girth weld. Finally, the machining process was modelled using the element removal technique and the residual stress field in the final weldment, i.e., the welded and machined DMW joint, was obtained after the various field variables were rebalanced in the FE model. 


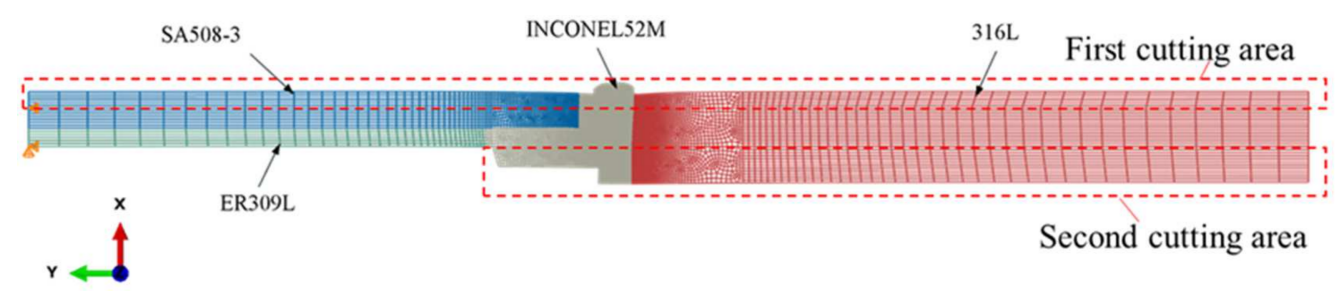

Figure 7. Model geometry and meshing used for the modelling analysis of the final machining process (in the current coordinate system, $\mathrm{x}, \mathrm{y}$ and $\mathrm{z}$ respectively represents the radial, axial and hoop direction of the tube, which also applies to all the other FE contour plots in this paper).

\subsection{Initial and Boundary Conditions}

During the modelling of the girth welding process, the initial temperature of the base materials was set at $25^{\circ} \mathrm{C}$, and that of the weld deposition $1377^{\circ} \mathrm{C}$ which is the liquidus of the filler metal. At the beginning of the FE modelling the element groups of the weld beads, as shown previously in Figure 6, were temporarily removed from the FE model, and they were later added back into the model following the welding sequence in reality as the modelling computation progressed. As the weld beads were brought back into the FE model one by one again, a body heat flux was also applied to simulate the heating effect from the electric arc of the automatic TIG welding process. The body heat flux $q$ was calculated using the following equation according to the welding process parameters given in Table 6:

$$
q=\frac{\eta U I}{S V}
$$

where $\eta$ is the thermal efficiency of the welding power for which a value of 0.76 was chosen, $U$ the voltage, $I$ the current, $S$ the weld bead area and $V$ the welding speed. The interpass cooling was allowed for $5 \mathrm{~min}$ for each welding pass, except for the last bead which was set at one hour in order to include the final cooling time. The maximum inter-layer temperature from the results of the FE calculation was $165.8^{\circ} \mathrm{C}$.

In the thermal analysis of the girth welding process, both convective and radiation heat flow were considered through all the free surfaces of the weldment. The convective heat transfer coefficient chosen was $15 \mathrm{~W} /\left(\mathrm{m}^{2}{ }^{\circ} \mathrm{C}\right)$ and the emissivity was 0.8 . In the mechanical analysis of the welding process, the displacement of the free end of the SA508-3 tube was constrained in the axial direction. The inner surface close to the free end of the SA508-3 tube was restrained for any radial displacement and its rotational degree of freedom about the axial axis was also constrained. In addition, annealing of the materials was also considered in the mechanical analysis, which eliminated the plastic strain history in the elements once their temperature had risen above $1101^{\circ} \mathrm{C}$.

In the modelling of the machining process, minimal constraint conditions were applied to the FE model, just to prevent the possible rigid body moment during the FE solution, without incurring any additional straining to the component for the final residual stress prediction and evaluation.

\section{Results and Discussion}

\subsection{FE prediction of Residual Stresses in As-Welded Condition}

Figure 8 shows the FE prediction of the von Mises stress distribution in the DMW joint of the mock-up after the multi-pass girth welding, whereas the residual stress distributions in the radial, axial and hoop directions are presented in Figure 9. It can be seen from Figure 8 that the maximum von Mises stress of up to $544.8 \mathrm{MPa}$ is mainly found in the weld crown area near the OD orientated towards the 316L stainless steel tube on the right hand side. It can also be appreciated that the maximum von Mises stress in the weld joint is well above the computed initial yield stress of the filler metal INCONEL52M alloy (361 MPa, see Table 15). This is believed to be due to the strain hardening effect of the material during the last stage of cooling. The von Mises stress contour is mainly localised near and on both 
side of the weld joint, with the high values noticeably diminishing from the girth weld towards the far fields.

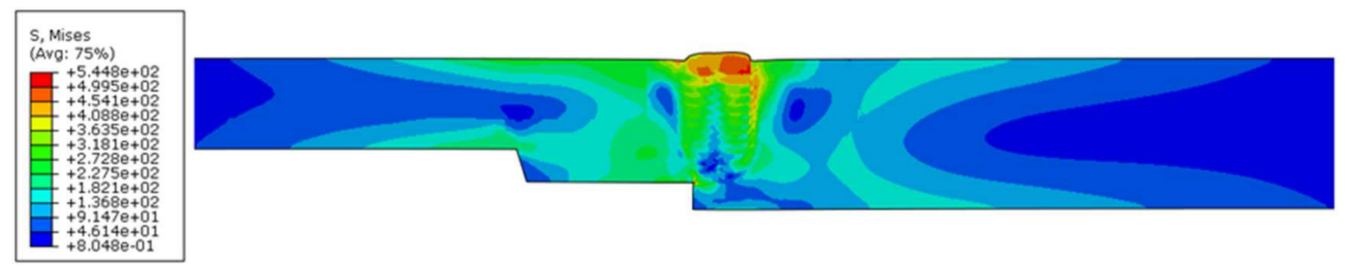

Figure 8. FE prediction of von Mises stress (MPa) distribution in the DMW joint after girth welding.

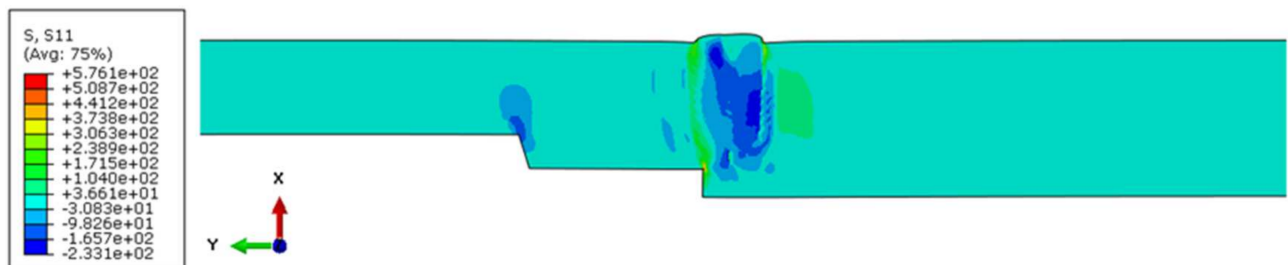

(a)

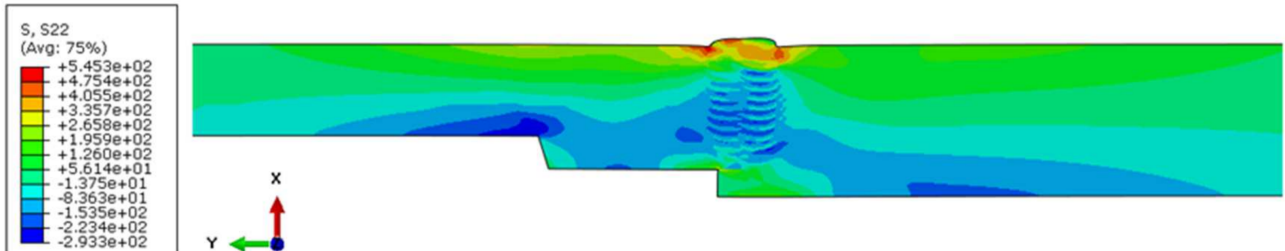

(b)
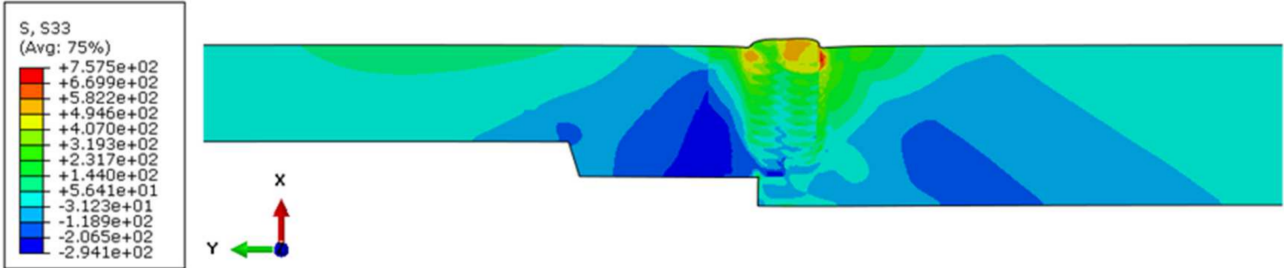

(c)

Figure 9. FE prediction of the radial (a), axial (b) and hoop (c) residual stress (MPa) distributions in the DMW joint after girth welding.

From Figure 9a it can be seen that residual stress in the radial direction, i.e., through the wall thickness, is mostly compressive in the weld area, with relatively low level of tensile residual stresses $(<300 \mathrm{MPa})$ being found near the fusion boundary on the SA508-3 side and in the parent material on the $316 \mathrm{~L}$ side of the girth weld. The high level of tensile residual stresses, up to about $576.1 \mathrm{MPa}$, is localised in very small areas near the corner on the ID close to the weld root and in the weld toes on the OD, which are caused by the geometric effect (stress concentration) and will be removed by the following machining operations. The as-welded axial residual stress distribution pattern in Figure 9b) exhibits high level tension in the weld crown and toe areas near the OD and low level tension near the weld root area in the ID. Whereas, in the mid-wall area of the girth weld joint, the axial residual stress is largely compressive with a visible fish-scale pattern that is caused by the corresponding weld bead depositions. A large area of tensile hoop residual stress is clearly seen in Figure 9c in the girth weld, which is also extended into the parent materials of SA508-3 and 316L on both sides, particularly towards the OD. In the adjacent areas to the weld joint, large areas of compressive hoop residual stresses are also seen, which are mainly confined in the parent materials extending towards the ID. It is interesting to note that at the bottom of the girth weld joint, especially near the weld root area, the hoop residual stress is also compressive. The extremely high level of tensile hoop residual stress 
found near the fusion line underneath the weld toe on the right hand side (757.5 MPa, 316L side) is believed to be caused by the severe deformation of the local material due to the ultra-high thermal gradients experienced during welding.

\subsection{FE prediction of Residual Stresses after Machining}

Figure 10 shows the FE prediction of the von Mises stress distribution in the DMW joint of the mock-up after machining, and Figure 11 gives the corresponding residual stress distributions in the radial, axial and hoop directions respectively. After machining the residual stresses were rebalanced through the FE computation into a new equilibrium state in the final specimen. Compared to that in the as-welded condition the residual stress state is profoundly changed both in terms of their values as well as distribution patterns after machining. The presence and influence of the fusion boundary on the residual stress distribution is now more visible, particularly on the 316L side to the left of the girth weld joint (Figures 10 and 11). It can be seen from Figure 10 that the maximum von Mises stress is located in the $316 \mathrm{~L}$ material along the fusion line of the girth weld. There are also two discontinued bands of relatively high von Mises stresses seen in the weld zone.

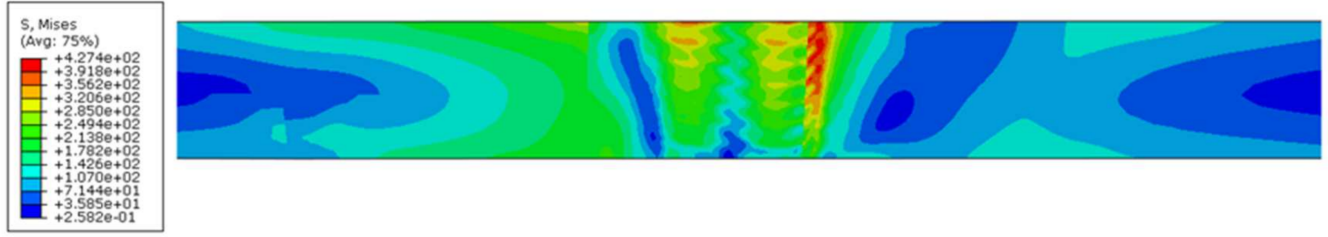

Figure 10. FE prediction of von Mises stress (MPa) distribution in the DMW joint after machining.
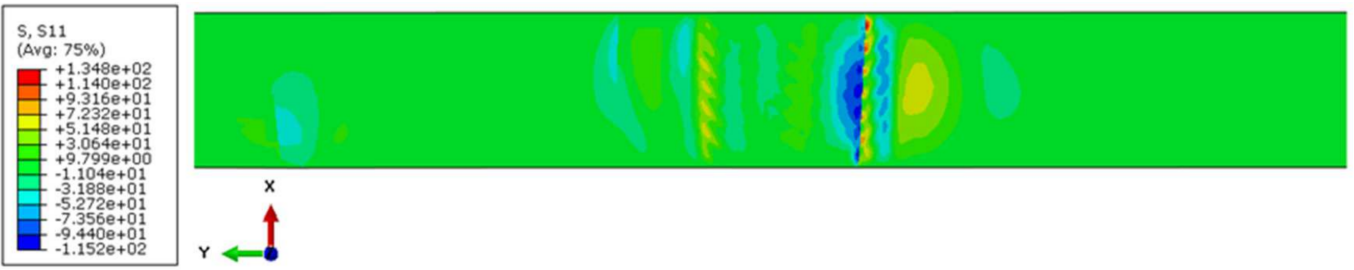

(a)
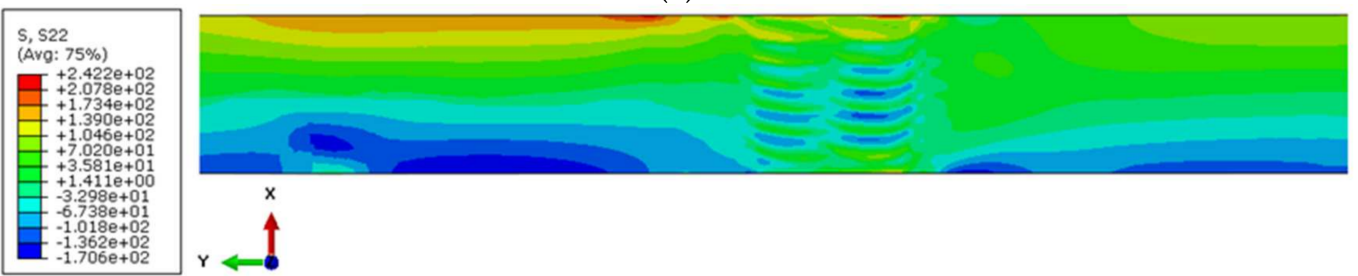
$r \ll$

(b)

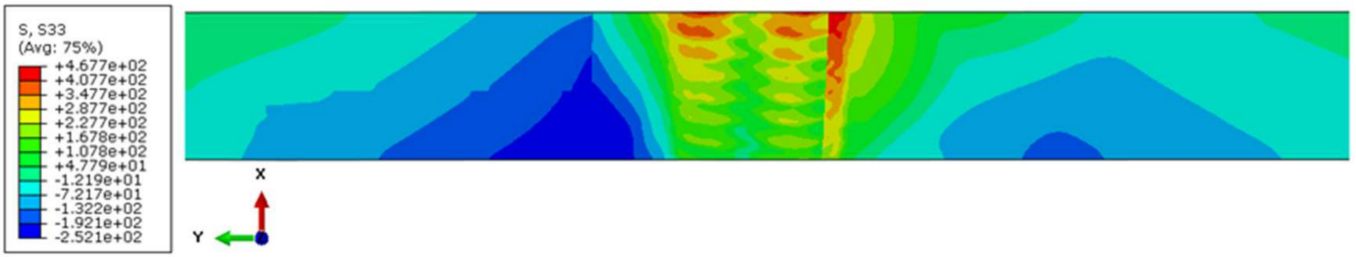

(c)

Figure 11. FE prediction of the radial (a), axial (b) and hoop (c) residual stress (MPa) distributions in the DMW joint after machining.

Moderately high values of tensile (up to $134.8 \mathrm{MPa}$ ) and compressive (down to $-115.2 \mathrm{MPa}$ ) radial residual stresses are all found along the fusion boundary between the girth weld and the 316L stainless steel tube, as can be seen in Figure 11a. Other than that, the level of radial residual stress is generally minimal in the rest areas of the machined 
component. The axial residual stress is mainly tensile in the OD as seen in Figure 11b with high values near the OD surface in the weld bead area as well as that of the SA508-3 tube to the left. Moving into the ID areas, the weld contains low level tensile residual stresses of about $70 \mathrm{MPa}$ whilst on either side of it, i.e., in the ID of SA508-3 and 316L part of the tube, compressive axial residual stresses are present. The two alternate tensioncompression axial residual stress bands found in the mid-wall of the girth weld are directly related to the corresponding weld beads being laid during the girth welding process, indicating the possible complex nature of the residual stress distribution in multi-pass welds. The hoop residual stress in the girth weld joint is mainly tensile through the wall thickness after machining, as can be seen in Figure 11c. Three banded areas of high tensile hoop residual stresses are observed, all starting from the OD with high values which then decrease gradually towards the ID, with one of such bands being in the $316 \mathrm{~L}$ parent material along the fusion boundary on the right and the other two being in the girth weld, again corresponding to the weld beads being laid during the girth welding process of the mock-up. Similar to the axial residual stress distribution pattern (Figure 11b), compressive hoop residual stresses are found on either side of the weld seam in the adjacent ID areas of both SA508-3 and 316L part of the tube (Figure 11c). It is worth noting that the low level of tensile residual stresses in the ID area of the weld and the compressive residual stresses in the ID of the adjacent SA508-3 and 316L material would be beneficial in inhibiting the development of SCC. While not in direct contact with corrosive medium, the OD of the DMW joint with high level of tensile residual stresses may favour fatigue crack initiation and growth.

Generally speaking, machining has removed the materials containing high value residual stresses in the weld crown, toe and root areas, which also resulted in residual stress redistribution due to the fact that a new equilibrium state has to be attained in the component after the machining operation. The degrees of reduction in various maximum residual stresses before and after machining are listed in Table 16. The most significant reduction is in the maximum radial residual stress, at $76.6 \%$, and the least reduction is in the maximum von Mises, at $21.5 \%$.

Table 16. Reduction of maximum weld residual stresses due to machining.

\begin{tabular}{cccc}
\hline \multirow{2}{*}{ Residual Stress } & \multicolumn{2}{c}{ Condition } & Reduction Due to \\
\cline { 2 - 3 } & As-Welded & After Machining & Machining, \% \\
\hline von Mises, $\mathrm{MPa}$ & 544.8 & 427.4 & 21.5 \\
Radial, $\mathrm{MPa}$ & 576.1 & 134.8 & 76.6 \\
Axial, $\mathrm{MPa}$ & 545.3 & 242.2 & 55.6 \\
Hoop, $\mathrm{MPa}$ & 757.5 & 467.7 & 38.3 \\
\hline
\end{tabular}

Meanwhile, it has to be pointed out that the distinctive nature of the weld residual stress distribution patterns that can be observed in Figures 10 and 11a,c, with large and sharp stress gradients along the fusion boundary between the girth weld and the 316L material on the right of the weld joint, is primarily due to the difference in material properties of the two materials involved, i.e., the girth weld being made of INCONEL52M alloy and the tube on the right hand side being 316L stainless steel. However, no similar residual stress distribution pattern is observed near the fusion boundary on the left hand side, and this is because the weld metal is joined with the buttering layer (also made of INCONEL52M alloy) of the SA508-3 tube (stress relief heat treated) which is of the same metal with the same material properties.

\subsection{Comparison of Residual Stresses between FE Prediction and Experimental Measurements}

As previously described in Section 3, both neutron diffraction and the contour method were used to characterise the residual stresses in the DMW joint of the nuclear safe-end mock-up. Figure 12 shows the hoop residual stress distribution in the DMW mock-up derived using the contour method. For clarity, the various regions of the weld joint are 
marked according to close examination of the weld macrograph. It can be seen that the hoop residual stresses in the multi-pass girth weld as well as the buttering layer are mainly tensile with high values localised towards the upper half of the wall with a maximum value of about $500 \mathrm{MPa}$. This is quite consistent with the FE prediction as shown in Figure 11c in which the maximum value is $467.7 \mathrm{MPa}$. On the other hand, compressive hoop residual stresses are found in the contour results on the left hand side of the weld seam, as shown in Figure 12, away from the buttering layer with the maximum value of about $-500 \mathrm{MPa}$ being found in the mid-wall area just above the cladding layer of the SA508-3 tube. However, looking at the FE prediction given in Figure 11c, compressive residual stresses are found on both sides of the weld seam, with a maximum value of about $-252 \mathrm{MPa}(50 \%$ lower than the contour measurement) being found on the ID area near the buttering layer of the SA5083 tube. The difference of compressive hoop residual stresses between the FE prediction and the contour measurement could be attributed to many factors, one of which would be the possible influence of the residual stresses from the cladding and buttering operations that might not have been completely removed by the stress relief heat treatment [13], and this was not considered in the current FE modelling analysis.

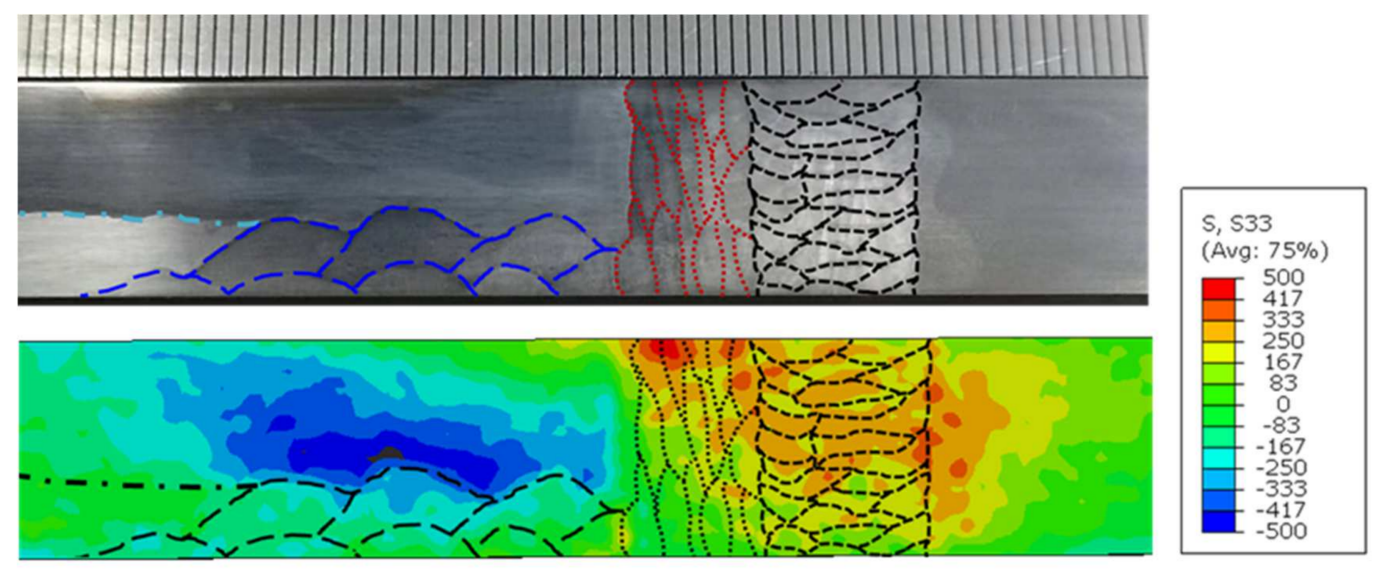

Figure 12. Hoop residual stress $(\mathrm{MPa})$ distribution obtained using the contour method: top-macrograph of the DMW joint, in which the cladding, buttering and the multi-pass girth weld areas are respectively marked with blue, red and black dotted lines; bottom-the contour plot of the hoop residual stress, in which the corresponding regions are also marked with dotted lines.

In order to make comparisons between the FE modelling prediction and the experimental measurements, three straight-line paths are defined across the DMW joint as shown in Figure 13, which are essentially along the three neutron scan lines marked in Figure 4. Hoop residual stress values are extracted along these paths from the FE prediction (Figure 11c) and the contour measurement (Figure 12), and plotted in Figure 14 together with the neutron diffraction measurement results. In general, the uncertainties in the estimated stresses using neutron diffraction were no greater than $\pm 25 \mathrm{MPa}$, to the point that the error bars do not extend beyond the data point markers. Uncertainties for the contour method arise from many origins (cutting, measurements, outlier removals, smoothing, mesh size, etc.) and there is currently no rigorous published procedure for quantifying them. It can be seen from Figure 14 that in general the hoop residual stresses obtained by neutron diffraction, contour method and FE simulation are fairly consistent. In fact, the agreement between the hoop residual stress distribution patterns in the weld and 316L material obtained from the three techniques is excellent for all the three paths evaluated, although slightly higher values are recorded by the neutron diffraction technique, in particular along paths 2 and 3 as shown in Figure 14b,c. 


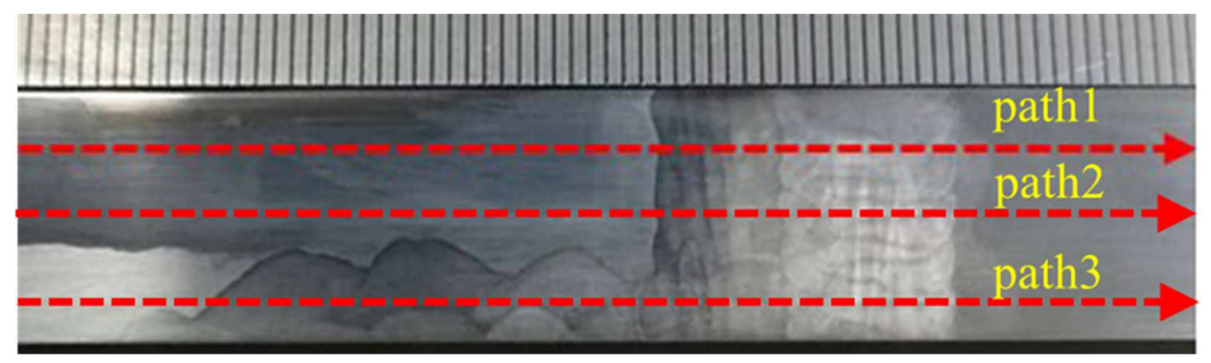

Figure 13. Three paths defined along the neutron scan lines (refer to Figure 4) across the DMW joint for residual stress evaluation and comparison.

Along path 1 for example, i.e., at the OD subsurface across the weld joint (see Figure 14a), both the contour method and the FE modelling gave maximum hoop residual stress near the weld fusion line on the 316L side at 388.2 and $453.2 \mathrm{MPa}$ respectively, whereas the neutron diffraction measured a similar value of $480.6 \mathrm{MPa}$ in the buttering zone near the SA508-3 side. In the buttering zone, the hoop residual stresses obtained from both the contour method and FE modelling decrease as the distance from the weld centre increases, and although with certain discrepancies their trends correlate well. On the other hand, the value of the single point measurement by neutron diffraction in this region is significantly higher for all the three paths (Figure 14), the reason for which is yet unknown. Again, it may be due to the fact that the stress relief heat treatment after cladding and buttering of the ferritic steel tube did not completely remove the residual stresses as expected.

In the SA508-3 region, the hoop residual stresses obtained from the contour method correlate very well with the neutron diffraction measurement, except for path 1 (Figure 14a), where the compressive hoop residual stresses (on three points) measured by neutron diffraction are significantly larger than that of the contour method. At the same time, it can be appreciated that the FE prediction of hoop residual stresses in this region shown in Figure 14 mostly deviates from the experimental measurements. However, it does show some good correlations between the FE prediction and the contour method in the following zones: 13-20 mm from the weld centre along path 1 (Figure 14a) and 22-30 $\mathrm{mm}$ from the weld centre along path 3 (Figure 14c).

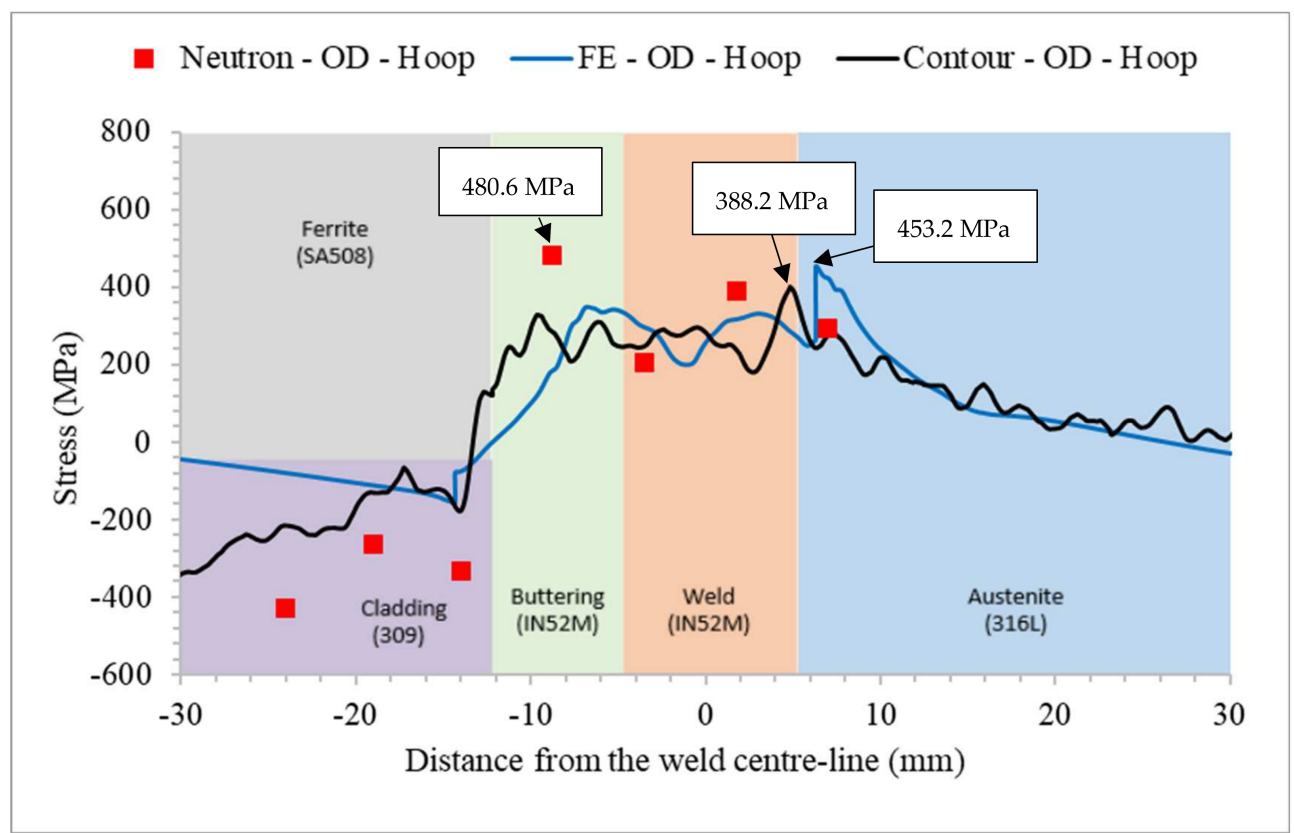

(a)

Figure 14. Cont. 


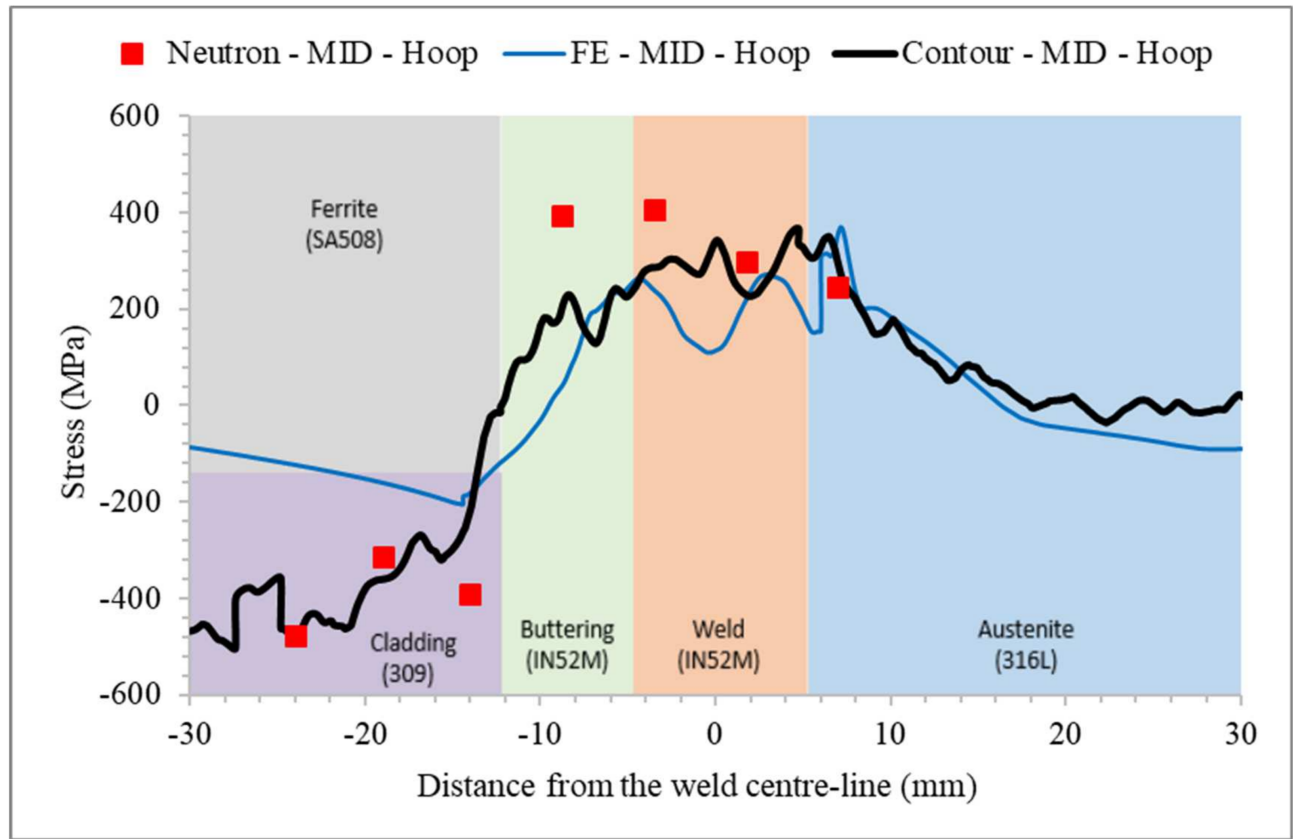

(b)

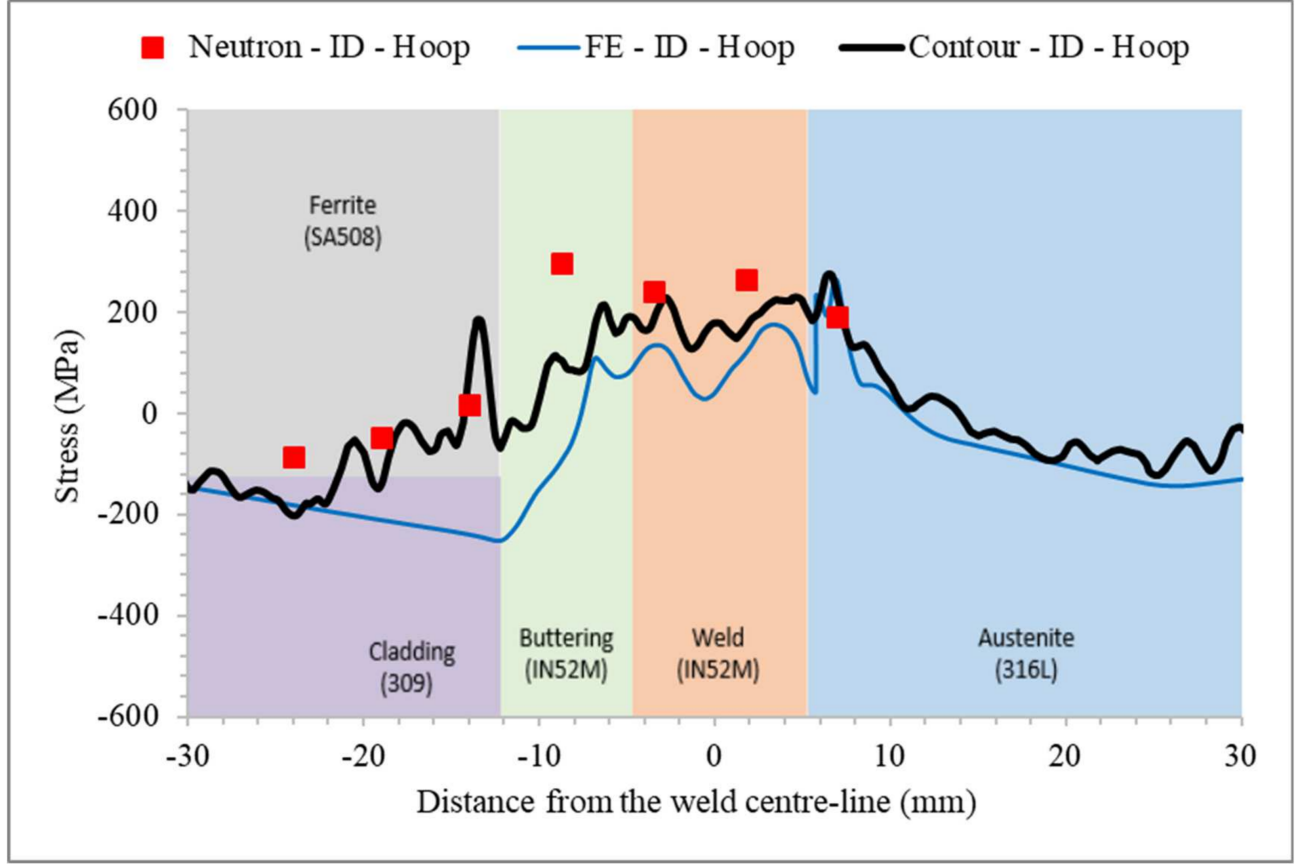

(c)

Figure 14. Comparison of hoop residual stresses along the three paths (as defined in Figure 13) between the FE prediction and experimental measurements: (a) along path 1 (near OD); (b) along path 2 (mid-wall); (c) along path 3 (near ID).

Through the above detailed examination and comparison of the results obtained using the three experimental and numerical techniques, namely neutron diffraction, the contour method and FE modelling, it can be stated that the level as well as the distribution of the residual stresses in the DMW joint have been revealed. These results and findings could be utilised as a starting point for the mitigation and control of the residual stresses in DMW joints for nuclear applications in future studies, for example through process optimisation, overlay welding [19] or thermal ageing [20]. 


\section{Conclusions}

In the current study, a mock-up of a nuclear safe-end DMW joint (SA508-3/316L) was manufactured, by closely following the standard procedures for nuclear applications. The weld residual stresses of the mock-up in its final machined condition were thoroughly characterised using neutron diffraction and the contour method. Alongside with the experimental work, a detailed finite element modelling exercise was also carried out for the prediction of the weld residual stresses resulting from the manufacturing processes (mainly the multi-pass girth welding and the final machining) of the DMW joint. From the analysis and comparison of the residual stress results between the FE prediction and experimental measurements, the following conclusions can be drawn:

(1) After multi-pass girth welding, high level tensile residual stresses are predicted by the FE simulation, mostly in the weld crown and weld toe areas on the OD and the sharp corner near the weld root on the ID of the DMW joint, with the maximum values well above $500 \mathrm{MPa}$ in the radial, axial and hoop directions. Although these values are significantly higher than the calculated initial yield stress of the filler metal due to strain hardening in the FE calculation and may represent an artifact, it is still recommended that precautions should be taken when these welded structures are put into service, preferably after the weld joints are treated for stress relief.

(2) After mechanical machining, the materials containing high value residual stresses including those geometrical stress concentrators have been removed and the residual stress field has reached a new equilibrium condition. Therefore, the maximum values of the various residual stresses are drastically reduced by up to $76.6 \%$ (in the radial direction), suggesting that having the weld crown and root machined off by cutting or grinding would be a good practice in reducing the detrimental high level tensile residual stresses in the welds.

(3) In the final machined condition, the FE results show low level of tensile residual stresses in the ID area of the weld seam and compressive residual stresses in the ID of the adjacent SA508-3 and 316L material, which would be beneficial in inhibiting the development of SCC. According to the FE calculation, high level tensile residual stresses are found predominantly in the hoop direction in and near the multi-pass girth weld joint, tending towards the OD with a maximum value of about $467.7 \mathrm{MPa}$. In the axial direction, relatively high tensile residual stresses are found near the OD surface of the weld joint, extending into the SA508-3 side with a maximum value of about $242.2 \mathrm{MPa}$ (about half of that in the hoop direction). In the radial direction, moderately high tensile residual stresses are found along the weld (INCONEL52M) and 316L fusion boundary with a maximum value of about 134.8 $\mathrm{MPa}$ (about half of that in the axial direction). While not in direct contact with corrosive medium, the high level of tensile residual stresses in the OD of the DMW joint may favour fatigue crack initiation and growth.

(4) The hoop residual stress distribution near the DMW joint of the mock-up as derived from the contour method bears close resemblance to that from the FE prediction. The maximum tensile hoop residual stress determined using the contour method was about 500 $\mathrm{MPa}$, which compares very well with the FE predicted value of about 467.7 MPa. Along the neutron scan line at the OD subsurface across the weld joint, both the contour method and the FE modelling gave maximum hoop residual stress near the weld fusion line on the 316L side at $388.2 \mathrm{MPa}$ and $453.2 \mathrm{MPa}$ respectively, whereas the neutron diffraction measured a similar value of $480.6 \mathrm{MPa}$ in the buttering zone near the SA508-3 side. Therefore, it is demonstrated that the contour method is also effective in quantifying residual stresses through the entire cut-plane, despite its drawbacks of being a destructive method.

(5) Detailed comparison of the hoop residual stresses along three paths across the girth weld joint near the OD, mid-wall and ID has revealed that residual stresses obtained using the three different methods, namely the neutron diffraction technique, the contour method and the FE modelling analysis, are reasonably consistent. In particular, the agreement between the hoop residual stress distribution patterns in the girth weld and the 316L material obtained from the three techniques is excellent for all the three paths evaluated, 
although slightly higher values are recorded by the neutron diffraction measurement along the mid-wall and ID. Therefore, it has been demonstrated that the methodology and techniques adopted in the current investigation of the residual stresses in the DMW joint of a nuclear safe-end mock-up are valid and effective. The minor discrepancies between the FE prediction and experimental measurement of the hoop residual stresses found in the buttering and SA508-3 areas are primarily due to the inadequate assumptions made in the FE modelling, i.e., by ignoring the inherent effect of the cladding and buttering residual stresses that may not have been completely removed by the stress relief heat treatment applied in practice. These conclusions are worthy of further investigation.

Author Contributions: Conceptualisation, methodology and supervision, S.Z.; writing-original draft preparation, Z.F., J.L. and S.W.; writing—revised draft, review and editing, S.Z., S.W., S.P., Z.F. and J.L.; FE modelling and formal analysis, Z.F. and J.L.; experiments, data analysis and comparison, S.P.; funding acquisition, S.Z. and L.L.; investigation, S.L. and L.L. All authors have read and agreed to the published version of the manuscript.

Funding: The work reported in this paper was financially supported by the Guangdong Major Project of Fundamental and Applied Fundamental Research (Project No. 2019B030302011 and 2020B0301030001), the Stable Supporting Fund of Science and Technology on Reactor Fuel and Materials Laboratory (Project No. JCKYS2019201073), the Guangdong Innovative and Entrepreneurial Research Team Program (Project No. 2016ZT06G025), and the Guangdong Natural Science Foundation (Project No. 2017B030306014).

Institutional Review Board Statement: Not applicable.

Informed Consent Statement: Not applicable.

Data Availability Statement: Not applicable.

Acknowledgments: Sincere thanks are given to Zhifeng Gong, Neutron Technology Department, Centre of Excellence for Advanced Materials, Dongguan, Guangdong Province, China, who participated in the neutron experiment and collated the raw data; to Tung Lik Lee and Saurabh Kabra, ISIS Facility, Rutherford Appleton Laboratory, Didcot, UK, who facilitated and supported the neutron experiment at ENGIN-X; and to Stephen Nneji, also from ISIS, who provided SScanSS-2 software support ISIS Facility, Rutherford Appleton Laboratory, CCLRC, Chilton, Didcot, OX11 0QX, UK. The ENGIN-X beamtime awarded through their Rapid Access Application (RB2000033) is also gratefully acknowledged.

Conflicts of Interest: The authors declare no conflict of interest.

\section{References}

1. Lee, K.S.; Kim, W.; Lee, J.G. Assessment of possibility of primary water stress corrosion cracking occurrence based on residual stress analysis in pressurizer safety nozzle of nuclear power plant. Nucl. Eng. Technol. 2012, 44, 343-354. [CrossRef]

2. Jenssen, A.; Norrgard, K.; Iagerstrom, J.; Embring, G.; Tice, D. Assessment of cracking in dissimilar metal welds. In Proceedings of the 10th International Symposium on Environmental Degradation of Materials in Nuclear Power Systems-Water Reactors, Lake Tahoe, NV, USA, 5-9 August 2001.

3. Toribio, J.; Vergara, D.; Lorenzo, M. Role of in-service stress and strain fields on the hydrogen embrittlement of the pressure vessel constituent materials in a pressurized water reactor. Eng. Fail. Anal. 2017, 82, 458-465. [CrossRef]

4. Coules, H.E.; Smith, D.J. Measurement of the residual stresses in a PWR Control Rod Drive Mechanism nozzle. Nucl. Eng. Des. 2018, 333, 16-24. [CrossRef]

5. Guo, R.; Xue, H.; Gong, X.Y. Influence of residual stress and heterogeneity on mechanical field at crack tips in safety end of nuclear power plant. Procedia Struct. Integr. 2018, 13, 2202-2209. [CrossRef]

6. Tan, L.; Zhao, L.Y.; Zhao, P.C.; Wang, L.L.; Pan, J.J.; Zhao, X.X. Effect of welding residual stress on operating stress of nuclear turbine low pressure rotor. Nucl. Eng. Technol. 2020, 52, 1862-1870. [CrossRef]

7. Liu, R.F.; Wang, J.C. Finite element analyses of the effect of weld overlay sizing on residual stresses of the dissimilar metal weld in PWRs. Nucl. Eng. Des. 2021, 372, 110959. [CrossRef]

8. Koo, Y.D.; Yoo, K.H.; Na, M.G. Estimation of residual stress in welding of dissimilar metals at nuclear power plants using cascaded support vector regression. Nucl. Eng. Technol. 2017, 49, 817-824. [CrossRef]

9. Song, T.K.; Kim, J.S.; Oh, C.Y.; Kim, Y.J.; Park, C.Y.; Lee, K.S. Through-wall welding residual stress profiles for dissimilar metal nozzle butt welds in pressurized water reactors. Fatigue Fract. Eng. Mater. Struct. 2011, 34, 624-641. [CrossRef] 
10. Song, T.K.; Kim, Y.B.; Kim, Y.J.; Oh, C.Y. Prediction of welding residual stress profile in dissimilar metal nozzle butt weld of nuclear power plant. Procedia Mater. Sci. 2014, 3, 784-789. [CrossRef]

11. Wen, L.J.; Guo, C.; Li, T.P.; Zhang, C.M. Stress analysis for reactor coolant pump nozzle of nuclear reactor pressure vessel. J. Appl. Math. Phys. 2013, 1, 62-64. [CrossRef]

12. Liu, C. Effects of material hardening model and lumped-pass method on welding residual stress simulation of J-groove weld in nuclear RPV. Eng. Comput. 2016, 5, 1435-1450. [CrossRef]

13. Dehaghi, E.M.; Moshayedi, H.; Sattari-Far, I.; Arezoodar, A.F. Residual stresses due to cladding, buttering and dissimilar welding of the main feed water nozzle in a power plant reactor. Int. J. Pressure Vessels Piping 2017, 152, 56-64. [CrossRef]

14. Lee, C.H.; Chang, K.H.; Park, J.U. Three-dimensional finite element analysis of residual stresses in dissimilar steel pipe welds. Nucl. Eng. Technol. 2013, 256, 160-168. [CrossRef]

15. Hill, M.R.; Olson, M.D.; Dewald, A.T. Biaxial residual stress mapping for a dissimilar metal welded nozzle. J. Press. Vessel Technol. 2016, 138, 9. [CrossRef]

16. Parmar, C.; Gill, C.; Pellereau, B.; Hurrell, P. Simulation of a multi-pass dissimilar metal nozzle to pipe weld using Abaqus 2D Weld GUI and comparison with measurements. In Proceedings of the ASME 2016 Pressure Vessels and Piping Conference, Vancuvre, BC, Canada, 17-21 July 2016.

17. Venkata, K.A.; Truman, C.E.; Smith, D.J. Characterising residual stresses in a dissimilar metal electron beam welded plate. Procedia Eng. 2015, 130, 973-985. [CrossRef]

18. Venkata, K.A.; Truman, C.E.; Smith, D.J.; Bhaduri, A.K. Characterising electron beam welded dissimilar metal joints to study residual stress relaxation from specimen extraction. Int. J. Press. Vessel. Pip. 2016, 139, 237-249. [CrossRef]

19. Chu, Q.; Kong, X.; Tan, W. Introducing compressive residual stresses into a stainless-steel T-pipe joint by an overlay weld. Metals 2021, 11, 1109. [CrossRef]

20. Ahonen, M.; Mouginot, R.; Sarikka, T.; Lindqvist, S.; Que, Z.; Ehrnstén, U.; Virkkunen, I.; Hänninen, H. Effect of thermal ageing at $400{ }^{\circ} \mathrm{C}$ on the microstructure of ferrite-austenite interface of nickel-base alloy narrow-gap dissimilar metal weld. Metals 2020, 10, 421. [CrossRef]

21. Sun, J.L. Record of Manufacturing Processes Workflow; No. P-WPS(P)-GTAW-159; Shanghai Electric Nuclear Power Equipment Co., Ltd.: Shanghai, China, 2019.

22. Liu, M. Completion Reports (I E II) of The Manufacture of Nuclear Safe-end Dissimilar Metal Weld Joints; China Nuclear Power Design Co., Ltd.: Shenzhen, China, 2019.

23. Santisteban, J.R.; Daymond, M.R.; Jamesb, J.A.; Edwardsb, L. ENGIN-X: A third-generation neutron strain scanner. J. Appl. Cryst. 2006, 39, 812-825. [CrossRef]

24. Prime, M.B.; Gonzales, A.R. The contour method: Simple 2-D mapping of residual stresses. In Proceedings of the 6th International Conference on Residual Stresses, Oxford, UK, 10-12 July 2000; IOM Communications; pp. 617-624.

25. Prime, M.B.; DeWald, A.T. The contour method. In Practical Residual Stress Measurement Methods; Schajer, G.S., Ed.; WileyBlackwell: Oxford, UK, 2013; pp. 109-138. [CrossRef]

26. Prime, M.B. Cross-sectional mapping of residual stresses by measuring the surface contour after a cut. J. Eng. Mater. Technol. 2001, 123, 162-168. [CrossRef] 